Article

\title{
Design, Synthesis and Biological Evaluation of Diosgenin-Amino Acid Derivatives with Dual Functions of Neuroprotection and Angiogenesis
}

\author{
Desheng Cai, Jinchai Qi, Yuqin Yang, Wenxi Zhang, Fei Zhou, Xiaohui Jia, Wenbo Guo, \\ Xuemei Huang, Feng Gao, Hongshan Chen, Tong Li, Guoping Li, Penglong Wang, \\ Yuzhong Zhang * and Haimin Lei * (D)
}

School of Chinese Pharmacy, Beijing University of Chinese Medicine, Beijing 102488, China; 20170931818@bucm.edu.cn (D.C.); 17862969559@163.com (J.Q.); yangyq5@163.com (Y.Y.); zhangwxnn@126.com (W.Z.); zf116318@163.com (F.Z.); 18811508865@163.com (X.J.); wb_guo@126.com (W.G.); hxm3928@163.com (X.H.); gaofeng_1996@126.com (F.G.); chs1314as@163.com (H.C.); 1t1755258545@163.com (T.L.); lgp2724760063@163.com (G.L.); wp1581@126.com (P.W.)

* Correspondence: zyz100102@126.com (Y.Z.); hm_lei@126.com (H.L.); Tel.: +86-10-8473-8645 (H.L.)

Received: 11 September 2019; Accepted: 5 November 2019; Published: 7 November 2019

\begin{abstract}
Diosgenin, a natural product with steroidal structure, has a wide range of clinical applications in China. It also shows great potential in the treatment of blood clots and nerve damage. To enhance the bioavailability as well as efficacy of diosgenin, eighteen diosgenin-amino acid derivatives were designed and synthesized. The neuroprotective effects of these compounds were evaluated by SH-SY5Y cell line and the biosafety was evaluated by H9c2 cell line. The results displayed that part of the derivatives' activities $\left(\mathrm{EC}_{50}<20 \mu \mathrm{M}\right)$ were higher than positive control edaravone $\left(\mathrm{EC}_{50}=21.60 \pm 3.04 \mu \mathrm{M}\right)$, among which, DG-15 $\left(\mathrm{EC}_{50}=6.86 \pm 0.69 \mu \mathrm{M}\right)$ exhibited the best neuroprotection. Meanwhile, biosafety evaluation showed that DG-15 had no cytotoxicity on H9c2 cell lines. Interestingly, combined neuroprotective and cytotoxic results, part of the derivatives without their protecting group were superior to compounds with protecting group. Subsequently, Giemsa staining and DAPI (4',6-diamidino-2-phenylindole) staining indicated that DG-15 had a protective effect on damaged SH-SY5Y cells by reducing apoptosis. Moreover, DG-15 showed a higher role in promoting angiogenesis at high concentrations $(4 \mathrm{mg} / \mathrm{mL})$ on the chorioallantoic membrane model. This finding displayed that DG-15 had dual functions of neuroprotection and angiogenesis, which provided further insight into designing agent for the application in treatment of ischemic stroke.
\end{abstract}

Keywords: diosgenin-amino acids derivatives; neuroprotection; angiogenesis; CAM model

\section{Introduction}

Ischemic stroke remains the third leading cause of mortality and long-term disability worldwide and thousands of people suffer strokes, living with some form of neurological impairment or disabilities each year. Ischemic stroke is related to insufficient blood supply in part or whole of the brain [1-3]. Inspired by this pathological occurrence, researchers have leaned towards enhancing the efficiency of angiogenesis [4], dissolving thrombus or salvaging ischemic neurons from irreversible injury [5] as the therapeutic strategy. Currently, many drugs, such as tissue plasminogen activator (tPA), heparin, urokinase, edaravone and nimodipine, were commonly used in clinical settings for preventing ischemic stroke. However, due to the contraindications (cardiopathy), serious side effects (hemorrhage or cardiac failure) and narrow therapeutic time window, only approximately $5 \%$ of patients full benefit from those drugs. More importantly, despite the fact that stroke is related to complex mechanisms in the brain, most pre-clinical trials were often performed using a single agent against single purported 
mechanism of action specifically targeting the stroke, which led to these efforts failing to provide significant benefit in clinical trials [6]. More effective and safe therapeutic strategies for the prevention and treatment of ischemic stroke are urgently needed. To broaden treatment targets and raise the cure rate, current opinion supports to develop an agent with multiple therapeutic targets.

Dioscorea Panthaica Prain et Burkill, as a clinical drug with a long history in China, was extracted from the rhizome of Dioscorea panthaica Prain et Burk and Dioscorea nipponica Makino, promoting blood circulation, removing blood stasis as well as anti-thrombosis. Diosgenin, as one of the important steroidal saponins in Dioscorea Panthaica Prain et Burkill, has a primary role in the synthesis of steroid hormones, contraceptives and cortisone, et al. [7-10]. Diosgenin has been reported a wide range of pharmacological activities, such as anti-inflammatory, anticancer, antiapoptotic, antihyperglycemia, antioxidant and antihypercholesterolemia activities [11-15]. Furthermore, modern pharmacological investigations have shown that diosgenin not only has significant effects of anti-thrombotic, anticoagulation but also protects neurons damaged by cerebral ischemia reperfusion [16-19]. Therefore, it has attracted increasing attention because of its great potential to reduce the risk of ischemic stroke by anti-thrombosis and neuroprotective activities. However, the low oral bioavailability due to the lipid solubility of diosgenin has become a major factor limiting its application [20,21]. It is noticeable that several reports have revealed that introducing some units at the C3 position with ester or ether bond significantly improved solubility and diverse physicochemical properties of diosgenin while maintaining the original advantages [22-25]. Amino acids, as an important organic compounds self-possessed of amine $\left(-\mathrm{NH}_{2}\right)$ and carboxylic $(-\mathrm{COOH})$ functional groups along with side chain particular to each amino acid [26], possess several advantages involving enhancing the selectivity, permeability as well as solubility and reducing the toxicity when it was introduced into a insoluble compounds [27-31]. Besides, amino acids successfully gained our attention because of its neuroprotection. For instance, L-type lysine could improve the function of central nervous tissue [32], glycine can reduce the damage of toxic substances generated during the ischemic processes and generate neuroprotective effects [33] and the neuroprotective effect of sarcosine is associated with changes in glycine transport and reduction of NR2B-containing NMDAR expression [34,35]. Therefore, they have inspired our interest in using diosgenin as the template parent to synthesize novel neuroprotective agents by combination with amino acids.

From the above, our present experiment was conducted to introduce different kinds of amino acids and obtained compounds with dual action on neuroprotection and angiogenesis. We successfully synthesized eighteen diosgenin-amino acid derivatives, characterizing the synthetic diosgenin-amino acid conjugation by ${ }^{1} \mathrm{H}-\mathrm{NMR},{ }^{13} \mathrm{C}-\mathrm{NMR}$ and HRMS, respectively. Moreover, the neuroprotective effect on SH-SY5Y (human neuroblastoma) cell line and biosafety of H9c2 (human cardiac myocytes) cell line were evaluated in vitro. In addition, Giemsa staining and DAPI staining were performed to observe the neuroprotective mechanism of the compounds with the best activity (DG-15). DG-15 also showed a good angiogenesis effect in the chorioallantoic membrane model (CAM). The results indicated that the major portion of derivatives showed a superior neuroprotective effect than raw materials and DG-15 has double efficacy of neuroprotection and angiogenesis.

\section{Results}

\subsection{Chemical Synthesis}

As shown in Scheme 1, all the designed derivatives were carried out in the following way. Eighteen diosgenin-amino acids derivatives were synthesized by esterification reaction and deprotection reaction, eight of which were novel and had not been previously reported.

We first chose diosgenin as a basic core and introduced nine different kinds of amino acids with protecting groups (Boc group or Cbz group) into its C-3 hydroxyl through the esterification reaction to obtain compounds 1-9 and the yield was 50-90\%. Subsequently, compounds 1-9 were further treated in dry dichloromethane (DCM) with trifluoroacetic (TFA), then the protecting groups were taken off 
and the compounds 10-18 were produced with $50-70 \%$. Table 1 shows the structure of all derivatives. The structures of all target compounds were determined by ${ }^{1} \mathrm{H}-\mathrm{NMR},{ }^{13} \mathrm{C}-\mathrm{NMR}$ and melting points, as well as by a detail HRMS analysis. Also, analysis by the optical rotation test demonstrated that the configuration of the derivatives $\mathbf{1 - 1 8}$ was consistent with the results of NMR.

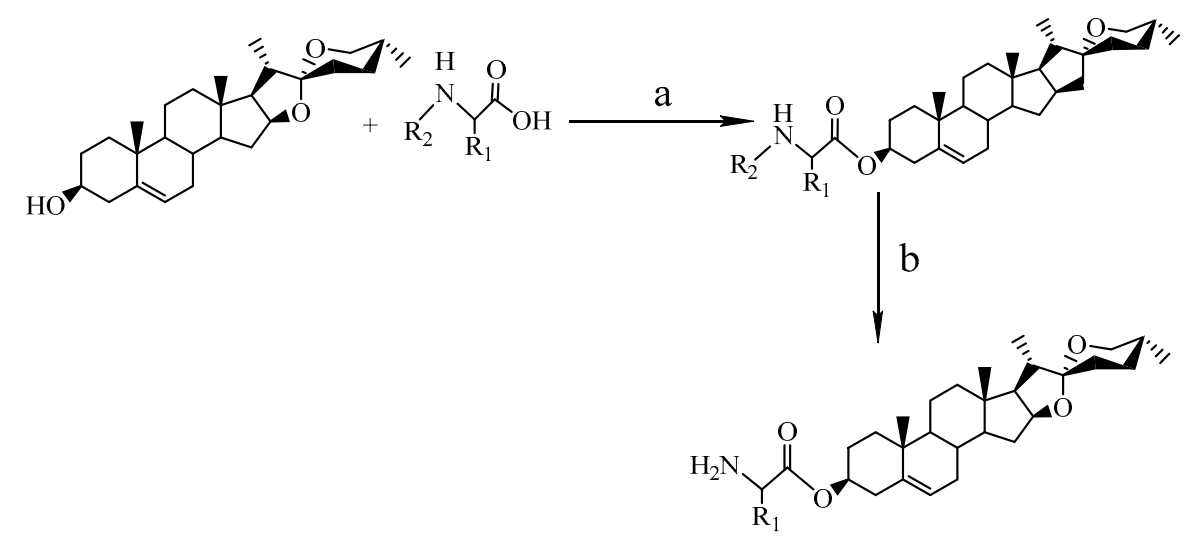

Scheme 1. Synthesis of the diosgenin-amino acids derivatives DG-1 to 18. Reagents and Conditions: (a) EDCI, DMAP, DCM, 12 h; (b) TFA, DCM, ice bath, 1 h (Boc protecting group); $\mathrm{Pd}(\mathrm{OH})_{2} / \mathrm{C}_{2} \mathrm{H}_{2}$, $\mathrm{MeOH}$, r.t. $12 \mathrm{~h}$ (Cbz protecting group).

Table 1. The structures of diosgenin-amino acids derivatives DG-1 to 18.

Compound


Molecules 2019, 24, 4025

4 of 19

Table 1. Cont.

Compound

DG-5

BOC-L-Leu

DG-6

BOC-L-Ile

DG-7

BOC-L-Phe

DG-8

CBZ-L-Val

DG-9

CBZ-L-Lys

DG-10

Gly

DG-11

L-Ala
Structure
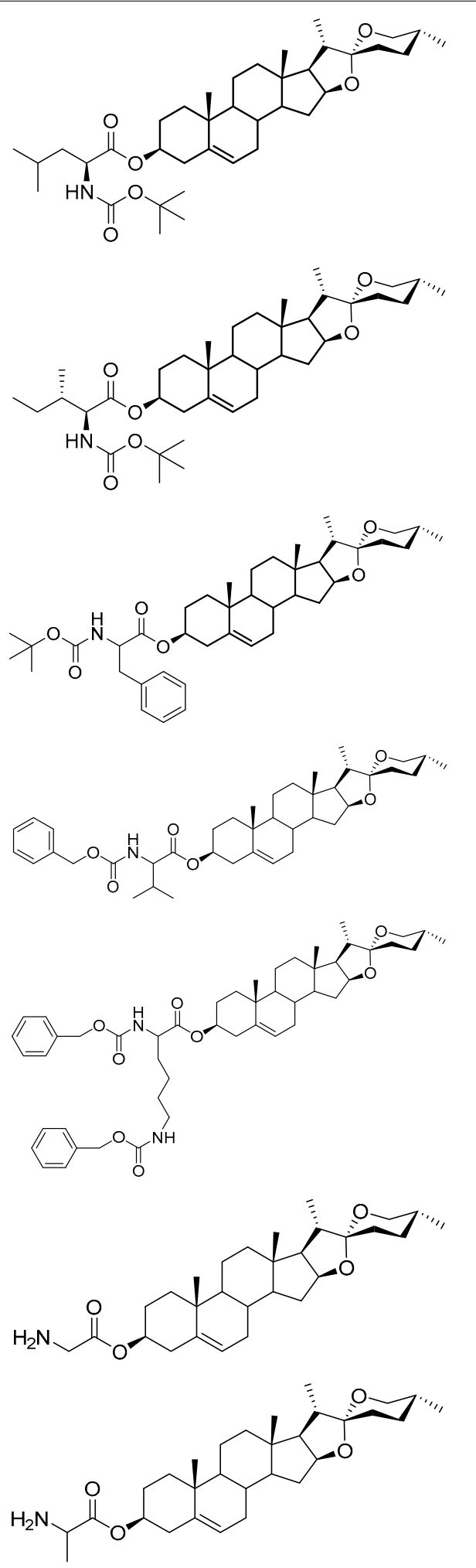
Table 1. Cont

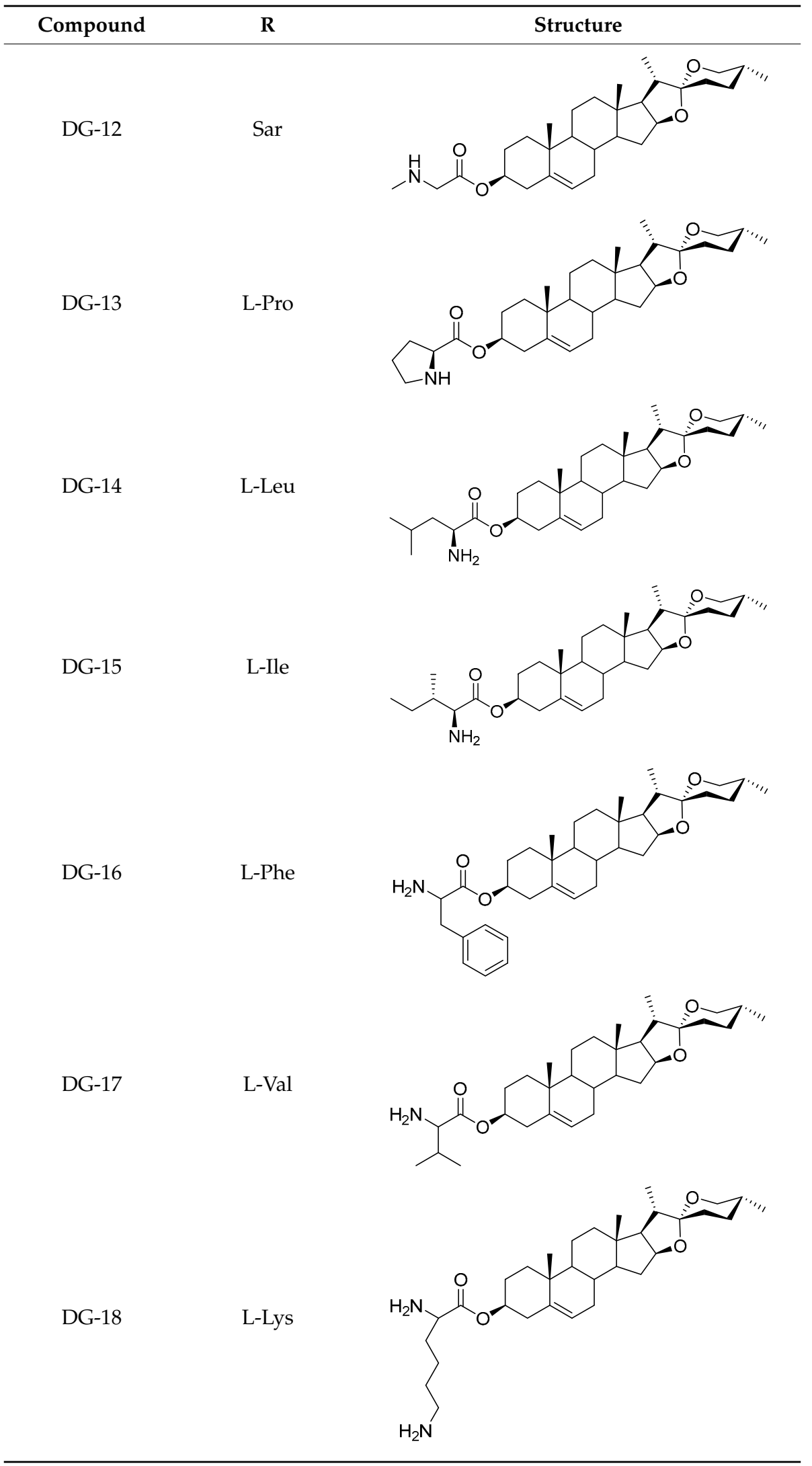




\subsection{Biological Activities}

\subsubsection{Neuroprotective Activity Test Using SH-HY5Y Cell}

A growing body of evidence supported that the occurrence of diverse brain diseases is closely related to oxidative stress [36] and the SH-SY5Y cells are recognized as a common model for evaluating the function of nerve cells [37]. In order to explore the neuroprotective activity of diosgenin-amino acids derivatives [38-42], the model of 2,4,5-Trihydroxybutyrophenone (TBHP)-induced neurotoxicity in SH-SY5Y cells has been used as an in vitro research platform in this study. The results were expressed as $\mathrm{EC}_{50}$ values in Table 2. As shown below, compared with the raw material diosgenin $\left(\mathrm{EC}_{50}>40 \mu \mathrm{M}\right)$, the neuroprotective effect of most compounds was distinctly enhanced. From an overall perspective, introduction of amino acid (without Boc group) could display lower $\mathrm{EC}_{50}$ values than the rest of compounds that were protected by the Boc group. For example, the $\mathrm{EC}_{50}$ of DG-13 and DG-15 in separate improved over 3 times and 2 times than DG-4 and DG-6. Among them, compounds DG-3, 5, 13, 15 and $16\left(\mathrm{EC}_{50}=15.20 \pm 0.96 ; 9.51 \pm 1.79 ; 7.22 \pm 1.58 ; 6.86 \pm 0.69 ; 11.38 \pm 2.62 \mu \mathrm{M}\right.$, respectively) performed well and acted more in neuroprotection than the positive drug edaravone $\left(\mathrm{EC}_{50}=21.60 \pm 3.04 \mu \mathrm{M}\right)$. In order to better select high-efficiency as well as low-toxic compounds from all the compounds, it is necessary to conduct biosafety evaluation. Therefore, compounds DG-13 and 15 with optimal activity were selected for further cytotoxicity evaluation.

Table 2. $\mathrm{EC}_{50}$ values of all the derivatives, raw materials and positive drug edaravone on SH-SY5Y for $24 \mathrm{~h}$. Based on three independent experiments, data were expressed as viability rate $\pm \mathrm{SD}(n=3)$.

\begin{tabular}{|c|c|c|c|c|c|c|}
\hline \multirow{2}{*}{ Compound } & \multicolumn{5}{|c|}{ Viability Rate (\%) } & \multirow{2}{*}{$\begin{array}{l}\mathrm{EC}_{50} \\
(\mu \mathrm{M})\end{array}$} \\
\hline & $3.12 \mu \mathrm{M}$ & $6.25 \mu \mathrm{M}$ & $12.50 \mu \mathrm{M}$ & $25.00 \mu \mathrm{M}$ & $50.00 \mu \mathrm{M}$ & \\
\hline Edaravone & 4.72 & 49.77 & 50.76 & 40.14 & 37.58 & $21.60 \pm 3.04$ \\
\hline DG & -4.01 & 26.90 & 7.75 & 16.13 & -4.80 & $>50$ \\
\hline DG-1 & -11.91 & 3.91 & 32.24 & 9.03 & 22.63 & $>50$ \\
\hline DG-2 & 17.31 & 4.90 & 10.41 & 17.66 & 19.36 & $>48.70 \pm 1.91$ \\
\hline DG-3 & 0.64 & 29.63 & 52.76 & 94.40 & 45.78 & $15.20 \pm 0.96$ \\
\hline DG-4 & -7.16 & 35.57 & 69.78 & 57.48 & 22.39 & $23.84 \pm 6.83$ \\
\hline DG-5 & 17.11 & 69.32 & 74.71 & 82.06 & 47.86 & $9.51 \pm 1.79$ \\
\hline DG-6 & 22.14 & 27.13 & 51.78 & 50.45 & 49.06 & $18.51 \pm 1.87$ \\
\hline DG-7 & -13.26 & 2.93 & 2.14 & 5.74 & -11.19 & $>50$ \\
\hline DG-8 & -7.49 & 12.93 & 49.74 & 35.24 & 14.87 & $38.09 \pm 6.68$ \\
\hline DG-9 & -6.02 & 25.03 & 49.87 & 36.28 & 8.33 & $36.24 \pm 8.67$ \\
\hline DG-10 & -5.22 & 17.87 & 12.57 & 5.55 & 0.08 & $>50$ \\
\hline DG-11 & -11.63 & 10.33 & 15.08 & 12.42 & 20.15 & $>50$ \\
\hline DG-12 & -25.18 & 42.36 & 38.07 & 24.61 & -14.68 & $>50$ \\
\hline DG-13 & 13.96 & 38.79 & 68.85 & 93.98 & 89.62 & $7.22 \pm 1.58$ \\
\hline DG-14 & -5.77 & 43.72 & 20.36 & 16.98 & 49.88 & $32.58 \pm 0.97$ \\
\hline DG-15 & 24.16 & 68.32 & 88.96 & 76.26 & 75.56 & $6.86 \pm 0.69$ \\
\hline DG-16 & 16.35 & 51.68 & 74.31 & 65.76 & 60.61 & $11.16 \pm 2.62$ \\
\hline DG-17 & -3.99 & -3.65 & 1.00 & -0.76 & -6.77 & $>50$ \\
\hline DG-18 & -37.10 & -53.53 & -97.67 & -103.66 & -107.92 & $>50$ \\
\hline
\end{tabular}

$\mathrm{EC}_{50}$ values: the data set was not listed when the EC50 values of compounds were higher than 50 for cells.

\subsubsection{Biosafety Evaluation Using H9c2 Cell}

The cytotoxicity of those superior derivatives (DG-13 and 15) in vitro were verified on rat embryonic cardiomyocytes (H9c2) by the MTT assay. The cell viability was summarized in Figure 1. It was found diosgenin was toxic under all treated groups. For example, cell viability was nearly $60 \%$ even under the concentration of $50 \mu \mathrm{M}$. While the cytotoxicity of the modified derivatives was significantly different. It was observed that the cytotoxicity of DG-13 was significantly enhanced compared with diosgenin and the survival rate was only $12 \%$ when the concentration was $25 \mu \mathrm{M}$. 
On the contrary, DG-15 had no inhibitory effect on cells at concentrations below $25 \mu \mathrm{M}$, which was better than that of diosgenin. Compound DG-13 and 15 have similar neuroprotective activities on SH-SY5Y, however their cytotoxicity is quite different. Thus, compound DG-15 with high effects and low poison was selected as a target compound for more in-depth research.

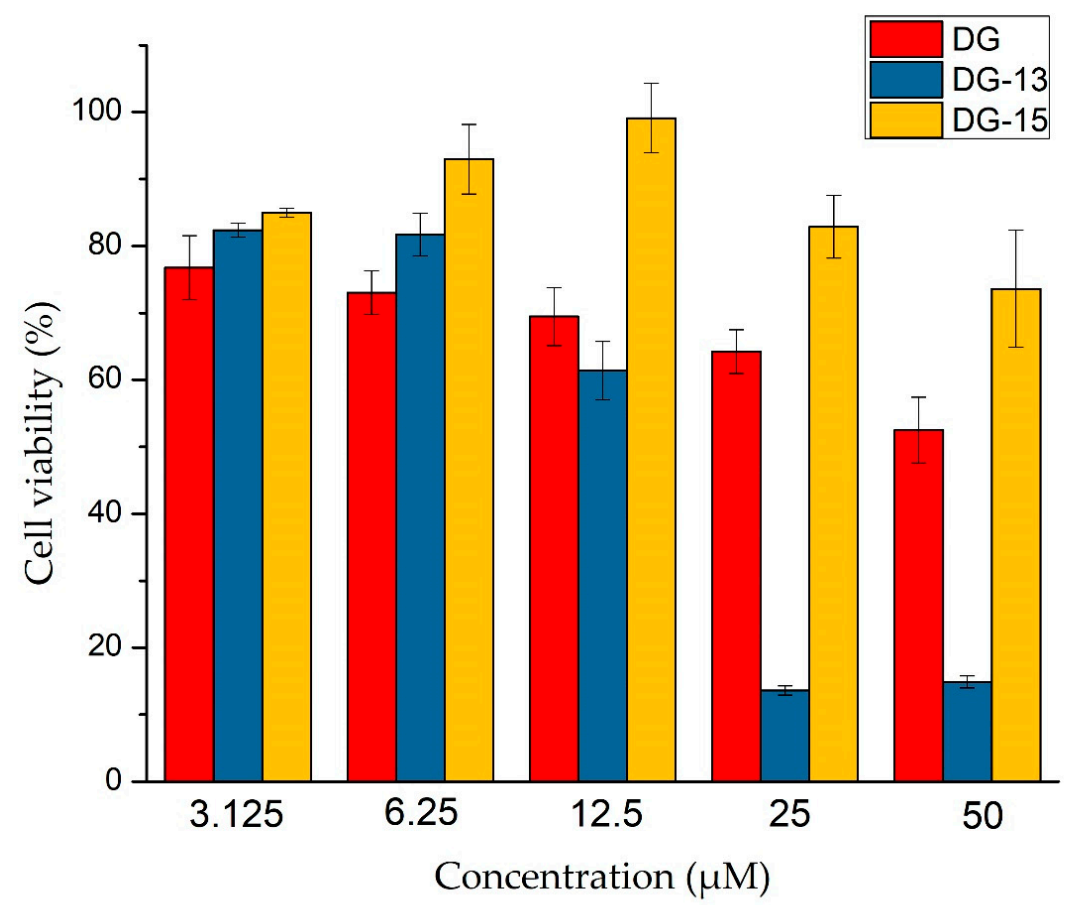

Figure 1. Cytotoxicity of diosgenin derivatives on $\mathrm{H} 9 \mathrm{c} 2$ for $24 \mathrm{~h}$. Data were expressed as cell viability based on three independent experiments $(n=3)$.

\subsubsection{Morphological Observation Using Giemsa and DAPI Staining}

The morphological change in SH-SY5Y cells induced by TBHP was analyzed by Giemsa and DAPI Staining. As we can see from Figure 2, compared with the control group (no treatment addition to the wells), SH-SY5Y cells treatment with TBHP showed an obvious changes in morphology and quantity, such as shrinkage of the cell bodies, appearance of nuclear fragmentation and disappearance of reticular formation, which suggested that the model of cell is valid. After treating damaged SH-SY5Y cells with $10,20,40 \mu \mathrm{M}$ of DG-15, the typical signs for apoptosis were reduced. With increasing concentration of DG-15, the number of cells increased significantly and the promotion of cell synapse formation obviously. The result indicated that DG-15 has a protective effect on SH-SY5Y cells damaged by TBHP in proper concentration range. Similarly, as shown in Figure 3, in three groups $(10,20,40 \mu \mathrm{M})$ the number of SH-SY5Y cells was increasingly larger and the cells of uniform size with apoptosis gradually reduced than the control group. Based on the above results, we found that the compound DG-15 could lead to an alleviated morphological lesion to injured SH-SY5Y cells at lower concentrations in vitro.

\subsubsection{Promotes Angiogenesis in CAM Assay}

The CAM model was used to further investigate the effects of DG-15 in angiogenesis [43-47]. The number of new vessels (inner diameter $<100 \mu \mathrm{m}$ ) radiating from the gelatin sponge were counted [48-50]. Macroscopic observation shown that the new blood vessels grow radially around the gelatin sponge after administration (Figure 4) and DG-15 could dramatically promote small angiogenesis in a dose dependent manner on CAM. As shown in Figure 5, the number of blood vessels increased by $60.61 \%$ and $80.30 \%$ at low and high concentrations $(1 \mathrm{mg} / \mathrm{mL}$ and $4 \mathrm{mg} / \mathrm{mL})$ of DG-15, respectively. The result implied that compound DG-15 has a certain role in promoting angiogenesis at high concentrations. 

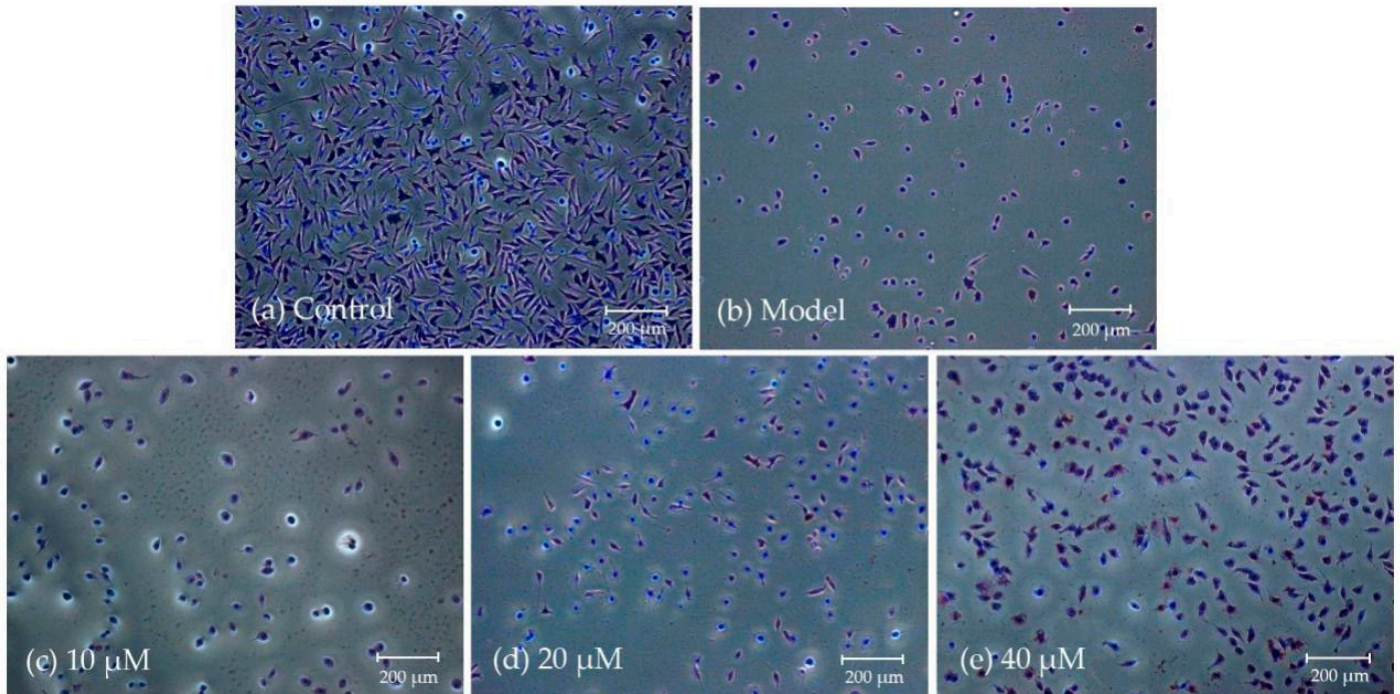

Figure 2. Giemsa staining on SH-SY5Y cells treated with compound DG-15 with different concentrations: (a) Control group; (b) TBHP treated cells; (c) $10 \mu \mathrm{M}$; (d) $20 \mu \mathrm{M}$; (e) $40 \mu \mathrm{M}$. The cell morphology was observed under the fluorescence microscope. The most representative fields were shown. Calibration bar: $200 \mu \mathrm{m}$.
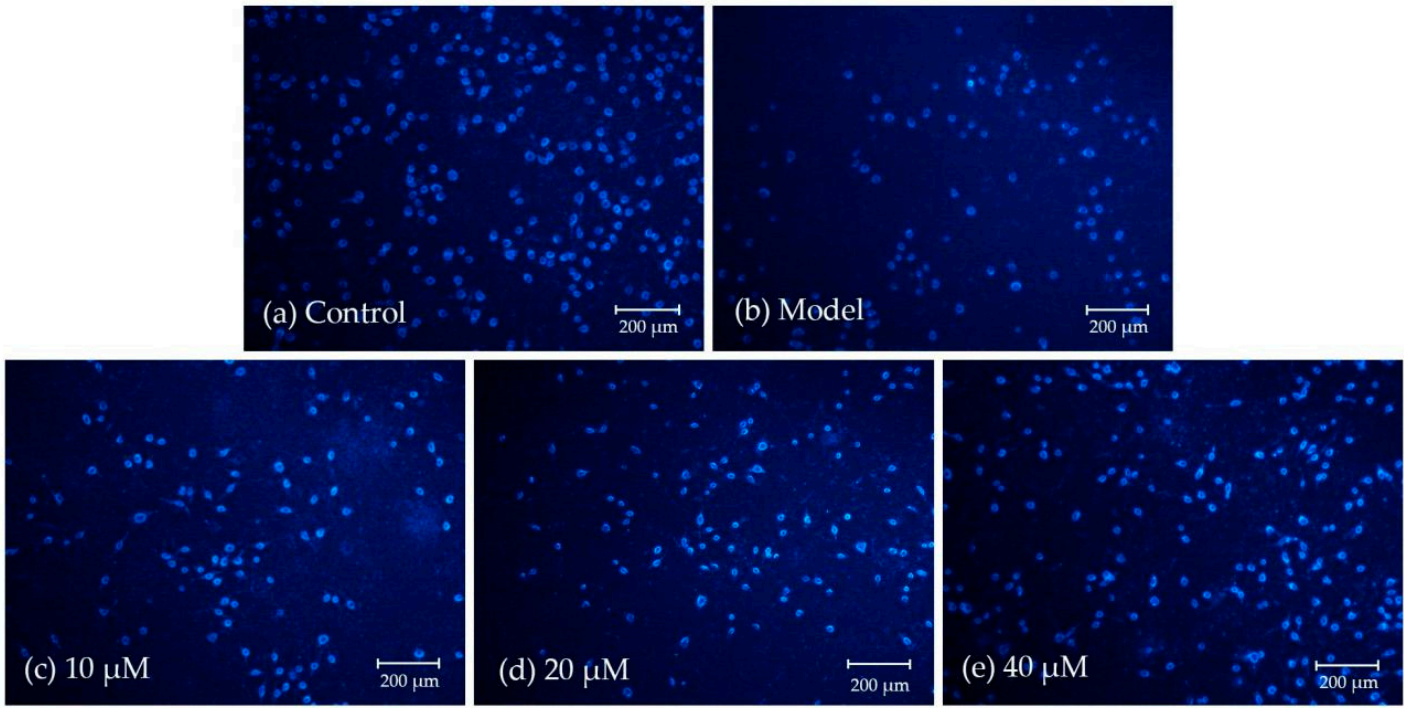

Figure 3. DAP staining on SH-SY5Y cells treated with compound DG-15 with different concentrations: (a) Control group; (b) TBHP treated cells; (c) $10 \mu \mathrm{M}$; (d) $20 \mu \mathrm{M}$; (e) $40 \mu \mathrm{M}$. The cell morphology was observed under the fluorescence microscope. The most representative fields were shown. Calibration bar: $200 \mu \mathrm{m}$.
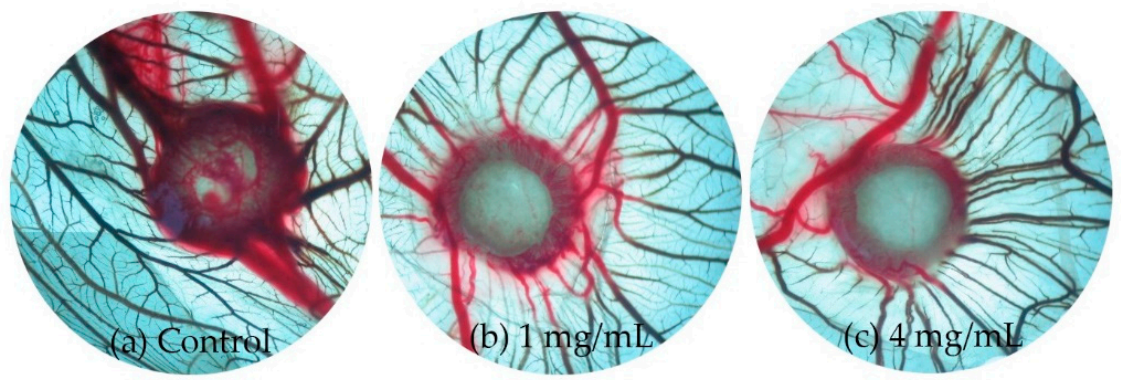

Figure 4. Compound DG-15 promoted angiogenesis in the CAM model with different concentrations: (a) Control group; (b) $1 \mathrm{mg} / \mathrm{mL}$; (c) $4 \mathrm{mg} / \mathrm{mL}$. 


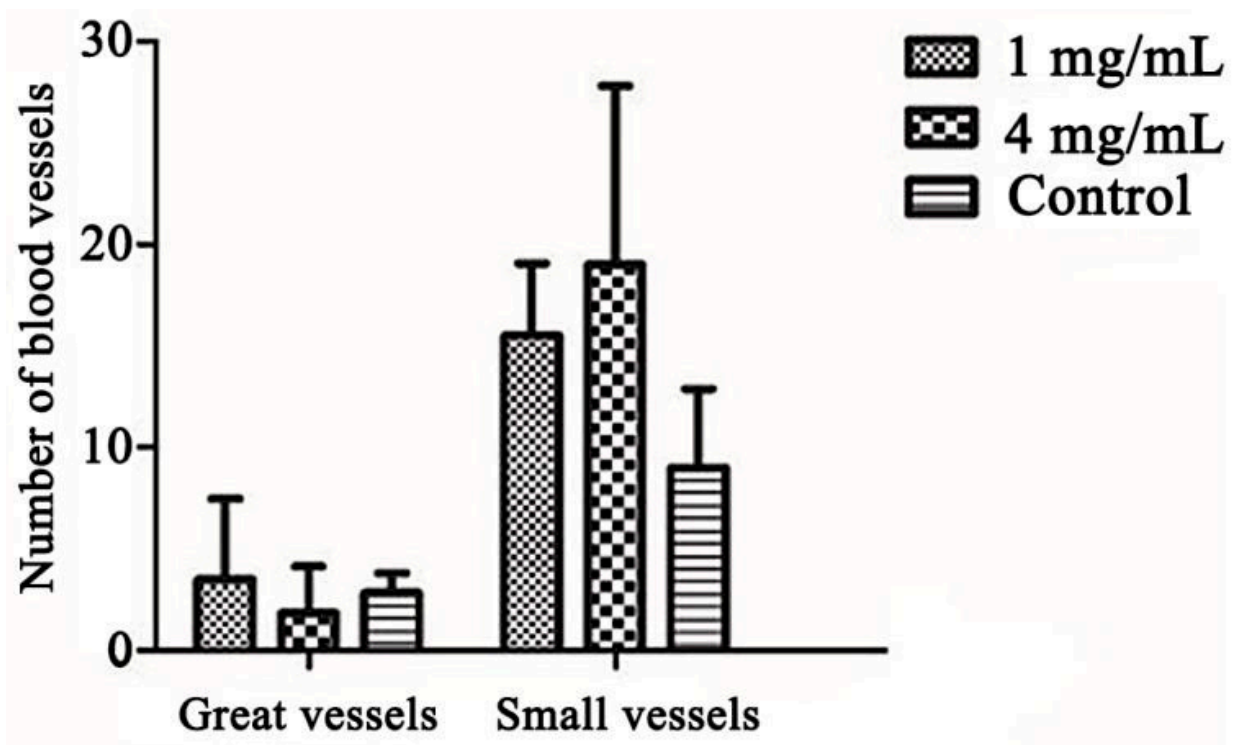

Figure 5. Compound DG-15 increased the number of blood vessels with different concentrations: $1 \mathrm{mg} / \mathrm{mL} ; 4 \mathrm{mg} / \mathrm{mL}$ and Control group.

\section{Discussion}

The treatment of ischemic stroke is still a worldwide problem. Research has focused on the repair of neurons. Also, recent pharmacological studies illustrated angiogenesis might be a crucial determinant of repairing damaged neurons after stroke and demonstrated a correlation with survival rate of stroke patients [41-55]. Inspired by biological characteristics of them, we introduced nine amino acids into diosgenin to enhance the function of neuroprotection and angiogenesis in this study. While some amino acids play essential roles in neuroprotection, it is a pity that the yield of these analogues was low than we expected. For instance, histidine (His) possess a relevant role in neuroprotection by reacting with copper ions and zinc, having an impact on proteasome functions and polyubiquitination reactions $[56,57]$. The effect of His was also ascribed to the inhibition of excessive L-glutamine transport to mitochondria [58], which was the reason of connection between the neuroprotective effects of His and strokes caused by oxidative stress. In addition, the results of neuroprotective activity evaluation indicated that the introduction of lysine, an alkaline amino acid, produced the higher cytotoxicity of compound (DG-18) than other compounds with neutral amino acids. Similar cytotoxicity occurs in many antitumor drugs with lysine residues [59]. Preliminary structure-activity relationships analysis indicated that, the derivatives containing $\mathrm{Cbz}$ group represented better neuroprotective activity than the compounds that have been stripped of its protective group ( $\mathrm{EC}_{50}$ : DG-8 $<$ DG-17; DG-9 < DG-18). This result was opposite of those of the BOC-protected compound.

\section{Materials and Methods}

\subsection{Materials and Instruments}

Diosgenin was purchased from KONO CHEM Co., Ltd. (Xian, China). Amino acid (Boc-Gly, Boc-L-Ala, Boc-Sar, Boc-L-Pro, Boc-L-Leu, Boc-L-Ile, Boc-L-Phe, Cbz-L-Val and Cbz-L-Lys) were obtained from Beijing Enochai Technology Co., Ltd. (Beijing, China), all reagents were required from suppliers with no purification measures. ${ }^{1} \mathrm{H}-\mathrm{NMR}$ and ${ }^{13} \mathrm{C}-\mathrm{NMR}$ spectra were recorded in $\mathrm{CDCl}_{3}$ or Acetone- $d_{6}$ solutions on a Bruker-500 spectrometer (Bruker, Dresden, Germany) with tetramethylsilane (TMS; TCI, Tokyo, Japan) as an internal reference. Mass spectra were acquired using a Thermo Scientific TMLTQ Orbitrap XL hybrid FTMS instrument (Thermo Technologies, New York, NY, USA) and an X-5 micro melting point apparatus (Beijing Tech Instrument Co., Ltd., Beijing, China). Giemsa, 6-diamidino-2-phenylindole (DAPI) were provided by Beijing Solarbio Science \& Technology Co. 
Ltd. (Beijing, China). SH-SY5Y cells and H9c2 cells were purchased from Institute of Peking Union Medical College (Beijing, China). Cellular morphologies were observed using an inverted fluorescence microscope (Olympus CKX53, Tokyo, Japan).

\subsection{Chemical Syntheses}

\subsubsection{The procedure for esterification at $\mathrm{C} 3-\mathrm{OH}($ method 1$)$}

The compound diosgenin (1 equiv.) and the protected amino acid with Boc or Cbz group (1.2 equiv.) were dissolved in dry dichloromethane (DCM, $10 \mathrm{~mL}$ ), the 1-Ethyl-3-(3-dimethylaminopropyl) carbodiimide hydrochloride (EDCI, 1.5 equiv.) and the 4-dimethylaminopyridine (DMAP, 0.5 equiv.) were added subsequently. Then the mixture was stirred at room temperature for $12 \mathrm{~h}$. Next, the solution was extracted 3 times with DCM to obtain crude product. Before purifying the crude produced by flash chromatography (silica gel, petroleum ether: acetone 10:1), the organic layer was dried by anhydrous sodium sulfate and evaporated under vacuum. The target compounds DG-1 to 9 were obtained.

\subsubsection{The procedure for deprotection reaction (method 2$)$}

After solving the diosgenin-amino acids derivatives DG-1 to 9 (0.33 equiv.) in dry DCM (1 equiv.) respectively, the trifluoroacetic acid (TFA, 0.1 equiv.) was added. The reaction was carried out in ice-water at $4{ }^{\circ} \mathrm{C}$ for $4 \mathrm{~h}$ and continuously stirred. Then the reaction mixture was evaporated under vacuum and diluted with DCM, then successively washed with saturated sodium bicarbonate solution and water. Finally, the organic layer was collected, dried and separated by flash chromatography with dichloromethane-acetone (10:1). The ${ }^{1} \mathrm{H}-\mathrm{NMR}$ and ${ }^{13} \mathrm{C}-\mathrm{NMR}$ spectra of compound $\mathbf{1 - 1 8}$ can be seen in the Supplementary Materials.

3ß-(N-Boc-glycine)-diosgenin (Compound DG-1). Compound DG-1 was obtained as white powder by method 1, yield: $78.5 \%$; m.p.: $218.7^{\circ} \mathrm{C}[\alpha]_{\mathrm{D}}^{25}=-89.72^{\circ}\left(\mathrm{c}=1.0 \mathrm{mg} / \mathrm{mL}, \mathrm{CHCl}_{3}\right) ;{ }^{1} \mathrm{H}-\mathrm{NMR}(500 \mathrm{MHz}$, Acetone- $\left.d_{6}\right): \delta(\mathrm{ppm}) 6.22(\mathrm{t}, J=5.5 \mathrm{~Hz}, 1 \mathrm{H}), 5.40(\mathrm{brs}, 1 \mathrm{H}), 4.60-4.54(\mathrm{~m}, 1 \mathrm{H}), 4.40-4.35(\mathrm{~m}, 1 \mathrm{H}), 3.77(\mathrm{~d}$, $J=6.0 \mathrm{~Hz}, 2 \mathrm{H}), 3.43-3.40(\mathrm{~m}, 1 \mathrm{H}), 3.29(\mathrm{t}, J=10.5 \mathrm{~Hz}, 1 \mathrm{H}), 2.32(\mathrm{~d}, J=8.0 \mathrm{~Hz}, 2 \mathrm{H}), 1.42(\mathrm{brs}, 9 \mathrm{H}$, Boc-H), 1.07(s, 3H), $0.96(\mathrm{~d}, J=7.0 \mathrm{~Hz}, 3 \mathrm{H}), 0.82(\mathrm{~s}, 3 \mathrm{H}), 0.77(\mathrm{~d}, J=6.5 \mathrm{~Hz}, 3 \mathrm{H}), 1.00-2.00(\mathrm{~m}, 22 \mathrm{H}$, Sterane Structure); ${ }^{13} \mathrm{C}-\mathrm{NMR}(125 \mathrm{MHz}$, Acetone- $d 6): \delta$ (ppm) $170.62\left(\mathrm{C1}^{\prime}\right), 156.96$ (C1"), 140.81 (C5), 123.25 (C6), 109.69 (C22), 81.59 (C16), 79.38 (C2"), 75.15 (C3), 67.38 (C26), 63.67, 57.40, 51.15, 43.33, 42.55, 40.60, 39.00, 37.91, 32.92, 32.72, 32.40, 31.28, 30.31, 30.16, 30.01, 29.85, 29.70, 28.73, 21.73, 19.82, 17.64, 16.83, 15.21; HRMS (ESI) $m / z: 572.3941[\mathrm{M}+\mathrm{H}]^{+}$, calcd for: $\mathrm{C}_{34} \mathrm{H}_{53} \mathrm{O}_{6} \mathrm{~N}$ 571.3941.

$3 \beta$-(N-Boc-L-alanine)-diosgenin (Compound DG-2). Compound DG-2 was obtained as white powder by method 1, yield: $78.6 \%$; m.p.: $218.9^{\circ} \mathrm{C}[\alpha]_{\mathrm{D}}^{25}=-86.96^{\circ}\left(\mathrm{c}=1.0 \mathrm{mg} / \mathrm{mL}, \mathrm{CHCl}_{3}\right) ;{ }^{1} \mathrm{H}-\mathrm{NMR}(500 \mathrm{MHz}$, $\left.\mathrm{CDCl}_{3}\right): \delta(\mathrm{ppm}) 5.37(\mathrm{brs}, 1 \mathrm{H}), 4.65(\mathrm{~s}, 1 \mathrm{H}), 4.38-4.42(\mathrm{~m}, 1 \mathrm{H}), 3.93(\mathrm{~s}, 1 \mathrm{H}), 3.85(\mathrm{~s}, 1 \mathrm{H}), 3.46(\mathrm{~d}$, $J=10.5 \mathrm{~Hz}, 1 \mathrm{H}), 3.36(\mathrm{t}, J=11.0 \mathrm{~Hz}, 1 \mathrm{H}), 2.91(\mathrm{~d}, J=11.5 \mathrm{~Hz}, 3 \mathrm{H}), 2.33(\mathrm{~s}, 2 \mathrm{H}), 2.16(\mathrm{~m}, 2 \mathrm{H}), 1.44(\mathrm{brs}$, 9H, Boc-H), $1.02(\mathrm{~s}, 3 \mathrm{H}), 0.97(\mathrm{~d}, J=7.0 \mathrm{~Hz}, 3 \mathrm{H}), 0.78(\mathrm{~s}, 6 \mathrm{H}), 1.00-2.00(\mathrm{~m}, 20 \mathrm{H}$, Sterane Structure); ${ }^{13} \mathrm{C}-\mathrm{NMR}\left(125 \mathrm{MHz}, \mathrm{CDCl}_{3}\right): \delta$ (ppm) $169.46\left(\mathrm{C1}^{\prime}\right), 155.64$ (C1"), 139.53 (C5), 122.78 (C6), 109.40 (C22), 80.93 (C16), 80.15 (C2"), 74.80 (C3), 66.97 (C26), 62.21, 56.55, 51.45, 50.65, 50.04, 41.74, 40.38, 39.84, 38.23, $37.02,36.84,35.71,32.16,31.97,31.52,31.06,30.43,28.94,28.43,27.87,20.94,19.45,17.27,16.41,14.65$. HRMS (ESI) $m / z: 586.9252[\mathrm{M}+\mathrm{H}]^{+}$, calcd for: $\mathrm{C}_{35} \mathrm{H}_{55} \mathrm{O}_{6} \mathrm{~N} 585.9252$.

$3 \beta$-(N-Boc-sarcosine)-diosgenin (Compound DG-3). Compound DG-3 was obtained as white powder by method 1, yield: $81.2 \%$; m.p.: $204.0^{\circ} \mathrm{C},[\alpha]_{\mathrm{D}}^{25}=-99.20^{\circ}\left(\mathrm{c}=1.0 \mathrm{mg} / \mathrm{mL}, \mathrm{CHCl}_{3}\right) ;{ }^{1} \mathrm{H}-\mathrm{NMR}(500 \mathrm{MHz}$, $\left.\mathrm{CDCl}_{3}\right): \delta(\mathrm{ppm}) 5.37(\mathrm{brs}, 1 \mathrm{H}), 4.67-4.63(\mathrm{~m}, 1 \mathrm{H}), 4.38-4.42(\mathrm{~m}, 1 \mathrm{H}), 3.46(\mathrm{~d}, J=8.5 \mathrm{~Hz}, 1 \mathrm{H}), 3.36(\mathrm{t}$, $J=11.0 \mathrm{~Hz}, 1 \mathrm{H}), 2.31(\mathrm{~d}, J=8.0 \mathrm{~Hz}, 2 \mathrm{H}), 2.16(\mathrm{~m}, 2 \mathrm{H}), 1.44(\mathrm{brs}, 9 \mathrm{H}$, Boc-H), $1.36(\mathrm{~d}, J=7.0 \mathrm{~Hz}, 3 \mathrm{H}), 1.03$ $(\mathrm{s}, 3 \mathrm{H}), 0.96(\mathrm{~d}, J=6.5 \mathrm{~Hz}, 3 \mathrm{H}), 0.78(\mathrm{~s}, 6 \mathrm{H}), 1.00-2.00\left(\mathrm{~m}, 22 \mathrm{H}\right.$, Sterane Structure); ${ }^{13} \mathrm{C}-\mathrm{NMR}(125 \mathrm{MHz}$, $\left.\mathrm{CDCl}_{3}\right): \delta(\mathrm{ppm}) 172.92\left(\mathrm{Cl}^{\prime}\right), 155.23\left(\mathrm{C} 1^{\prime \prime}\right), 139.57$ (C5), 122.71 (C6), 109.41 (C22), $80.92(\mathrm{C} 16), 74.98$ (C3), 66.97 (C26), 62.21, 56.56, 50.05, 49.49, 41.74, 40.39, 39.85, 38.03, 37.01, 36.85, 32.17, 31.97, 31.52, 
$30.43,28.94,28.47,27.77,20.94,19.46,18.94,17.27,16.41,14.65$. HRMS (ESI) $m / z: 586.4225[\mathrm{M}+\mathrm{H}]^{+}$, calcd for: $\mathrm{C}_{35} \mathrm{H}_{55} \mathrm{O}_{6} \mathrm{~N} 585.4225$.

$3 \beta$-(N-Boc-L-proline)-diosgenin (Compound DG-4). Compound DG-4 was obtained as white powder by method 1, yield: $80.2 \%$; m.p.: $183.4^{\circ} \mathrm{C},[\alpha]_{\mathrm{D}}^{25}=-106.67^{\circ}\left(\mathrm{c}=1.0 \mathrm{mg} / \mathrm{mL}, \mathrm{CHCl}_{3}\right) ;{ }^{1} \mathrm{H}-\mathrm{NMR}(500 \mathrm{MHz}$, $\left.\mathrm{CDCl}_{3}\right): \delta(\mathrm{ppm}) 5.37(\mathrm{brs}, 1 \mathrm{H}), 4.62(\mathrm{~d}, J=9.0 \mathrm{~Hz}, 1 \mathrm{H}), 4.38-4.43(\mathrm{~m}, 1 \mathrm{H}), 4.17-4.28(\mathrm{~m}, 1 \mathrm{H}), 2.31(\mathrm{~d}$, $J=7.0 \mathrm{~Hz}, 2 \mathrm{H}), 2.16(\mathrm{~m}, 2 \mathrm{H}), 1.44(\mathrm{brs}, 9 \mathrm{H}, \mathrm{Boc}-\mathrm{H}), 1.03(\mathrm{~d}, J=5.0 \mathrm{~Hz}, 3 \mathrm{H}), 0.97(\mathrm{~d}, J=7.0 \mathrm{~Hz}, 3 \mathrm{H})$, $0.78(\mathrm{~s}, 6 \mathrm{H}), 1.00-2.00\left(\mathrm{~m}, 28 \mathrm{H}\right.$, Sterane Structure); ${ }^{13} \mathrm{C}-\mathrm{NMR}\left(125 \mathrm{MHz}, \mathrm{CDCl}_{3}\right): \delta(\mathrm{ppm}) 172.73\left(\mathrm{C1}^{\prime}\right)$, 154.03 (C1"), 139.61 (C5), 122.70 (C6), 109.41 (C22), 80.93 (C16), 74.48 (C3), 66.98 (C26), 62.22, 59.40, 56.55, 50.06, 46.70, 46.48, 41.75, 40.39, 39.85, 37.06, 32.18, 31.98, 31.53, 31.12, 30.44, 30.12, 28.94, 28.59, 28.52, 27.77, 24.40, 23.68, 20.95, 19.48, 17.27, 16.41, 14.66. HRMS (ESI) $m / z: 612.4243$ [M + H] ${ }^{+}$, calcd for: $\mathrm{C}_{37} \mathrm{H}_{57} \mathrm{O}_{6} \mathrm{~N} 611.4243$.

$3 \beta$-(N-Boc-L-leucine)-diosgenin (Compound DG-5). Compound DG-5 was obtained as white powder by method 1, yield: $86.3 \%$; m.p.: $150.6^{\circ} \mathrm{C}[\alpha]_{\mathrm{D}}^{25}=-76.77^{\circ}\left(\mathrm{c}=1.0 \mathrm{mg} / \mathrm{mL}, \mathrm{CHCl}_{3}\right) ;{ }^{1} \mathrm{H}-\mathrm{NMR}(500 \mathrm{MHz}$, $\left.\mathrm{CDCl}_{3}\right): \delta(\mathrm{ppm}) 5.37(\mathrm{brs}, 1 \mathrm{H}), 4.88(\mathrm{~d}, J=8.5 \mathrm{~Hz}, 1 \mathrm{H}), 4.62-4.69(\mathrm{~m}, 1 \mathrm{H}), 4.40-4.45(\mathrm{~m}, 1 \mathrm{H}), 4.26-4.28$ $(\mathrm{m}, 1 \mathrm{H}), 3.47-3.50(\mathrm{~m}, 1 \mathrm{H}), 3.39(\mathrm{t}, J=11.0 \mathrm{~Hz}, 1 \mathrm{H}), 2.33(\mathrm{~d}, J=7.5 \mathrm{~Hz}, 2 \mathrm{H}), 2.01(\mathrm{~m}, 2 \mathrm{H}), 1.46$ (brs, 9H, Boc-H), $1.06(\mathrm{~s}, 3 \mathrm{H}), 0.95-1.00(\mathrm{~m}, 9 \mathrm{H}), 0.80(\mathrm{t}, J=3 \mathrm{~Hz}, 6 \mathrm{H}), 1.00-2.00(\mathrm{~m}, 23 \mathrm{H}$, Sterane Structure); ${ }^{13} \mathrm{C}-\mathrm{NMR}\left(125 \mathrm{MHz}, \mathrm{CDCl}_{3}\right): \delta(\mathrm{ppm}) 173.04\left(\mathrm{C1}^{\prime}\right), 155.55$ (C1"), 139.65 (C5), 122.66 (C6), 109.41 (C22), 80.94 (C16), 79.81 (C2"), 74.87 (C3), 66.98 (C26), 62.22, 56.57, 52.38, 50.06, 42.10, 41.75, 40.39, 39.86, 38.09, $37.03,36.86,32.18,31.98,31.53,30.44,28.95,28.47,27.81,24.95,22.99,22.15,20.95,19.48,17.28,16.42$, 14.66. HRMS (ESI) $m / z: 628.4568[\mathrm{M}+\mathrm{H}]^{+}$, calcd for: $\mathrm{C}_{38} \mathrm{H}_{61} \mathrm{O}_{6} \mathrm{~N} 627.4568$.

$3 \beta$-(N-Boc-L-isoleucine)-diosgenin (Compound DG-6). Compound DG-6 was obtained as white powder by method 1, yield: $82.4 \%$; m.p.: $161.4^{\circ} \mathrm{C},[\alpha]_{\mathrm{D}}^{25}=-75.79^{\circ}\left(\mathrm{c}=1.0 \mathrm{mg} / \mathrm{mL}, \mathrm{CHCl}_{3}\right) ;{ }^{1} \mathrm{H}-\mathrm{NMR}(500 \mathrm{MHz}$, $\left.\mathrm{CDCl}_{3}\right): \delta(\mathrm{ppm}) 5.37(\mathrm{brs}, 1 \mathrm{H}), 5.03(\mathrm{~d}, J=8.5 \mathrm{~Hz}, 1 \mathrm{H}), 4.63-4.67(\mathrm{~m}, 1 \mathrm{H}), 4.38-4.43(\mathrm{~m}, 1 \mathrm{H}), 3.45-3.48$ $(\mathrm{m}, 1 \mathrm{H}), 3.37(\mathrm{t}, J=11.0 \mathrm{~Hz}, 1 \mathrm{H}), 2.30-2.35(\mathrm{~m}, 2 \mathrm{H}), 1.95-2.01(\mathrm{~m}, 2 \mathrm{H}), 1.44$ (brs, 9H, Boc-H), $1.04(\mathrm{~s}, 3 \mathrm{H})$, $0.97(\mathrm{~d}, J=7.0 \mathrm{~Hz}, 3 \mathrm{H}), 0.90-0.94(\mathrm{~m}, 6 \mathrm{H}), 0.78(\mathrm{t}, J=3.0 \mathrm{~Hz}), 1.00-2.00(\mathrm{~m}, 24 \mathrm{H}$, Sterane Structure); ${ }^{13} \mathrm{C}-\mathrm{NMR}\left(125 \mathrm{MHz}, \mathrm{CDCl}_{3}\right): \delta(\mathrm{ppm}) 171.82\left(\mathrm{C1}^{\prime}\right), 155.71(\mathrm{C} 1 "), 139.60(\mathrm{C} 5), 122.74(\mathrm{C} 6), 109.42(\mathrm{C} 22)$, 80.94 (C16), 79.76 (C2"), 74.90 (C3), 66.99 (C26), 62.22, 58.04, 56.57, 50.07, 41.75, 40.40, 39.86, 38.33, 38.22, 37.03, 36.86, 32.18, 31.98, 31.52, 30.44, 28.95, 28.49, 27.88, 25.25, 20.95, 19.48, 17.28, 16.42, 15.64, 14.66, 11.90. HRMS (ESI) $m / z: 628.4563[\mathrm{M}+\mathrm{H}]^{+}$, calcd for: $\mathrm{C}_{38} \mathrm{H}_{61} \mathrm{O}_{6} \mathrm{~N} 627.4563$.

$3 \beta$-(N-Boc-L-phenylalanine)-diosgenin (Compound DG-7). Compound DG-7 was obtained as white powder by method 1, yield: $80.1 \%$; m.p.: $163.4{ }^{\circ} \mathrm{C},[\alpha]_{\mathrm{D}}^{25}=-84.03^{\circ}\left(\mathrm{c}=1.0 \mathrm{mg} / \mathrm{mL}, \mathrm{CHCl}_{3}\right) ;{ }^{1} \mathrm{H}-\mathrm{NMR}$ $\left(500 \mathrm{MHz}, \mathrm{CDCl}_{3}\right): \delta(\mathrm{ppm}) 7.14-7.30(\mathrm{~m}, 5 \mathrm{H}), 5.36$ (brs, $\left.1 \mathrm{H}\right), 4.97(\mathrm{~d}, J=8.5 \mathrm{~Hz}, 1 \mathrm{H}), 4.59-4.63$ $(\mathrm{m}, 1 \mathrm{H}), 4.54-4.58(\mathrm{~m}, 1 \mathrm{H}), 4.39-4.53(\mathrm{~m}, 1 \mathrm{H}), 3.46-3.48(\mathrm{~m}, 1 \mathrm{H}), 3.37(\mathrm{t}, J=11 \mathrm{~Hz}, 1 \mathrm{H}), 3.03-3.11$ (m, 2H), 2.22-2.25 (m, 2H), 1.96-2.02 (m, 2H), 1.42 (brs, 9H, Boc-H), $1.02(\mathrm{~s}, 3 \mathrm{H}), 0.97(\mathrm{~d}, J=7.0 \mathrm{~Hz}$, $6 \mathrm{H}), 0.79(\mathrm{~d}, J=4.5 \mathrm{~Hz}, 6 \mathrm{H}), 1.00-2.00\left(\mathrm{~m}, 20 \mathrm{H}\right.$, Sterane Structure); ${ }^{13} \mathrm{C}-\mathrm{NMR}\left(125 \mathrm{MHz}, \mathrm{CDCl}_{3}\right): \delta$ (ppm) 171.41(C1'), 155.21 (C1"), 139.60 (C5), 136.27 (Ar-C), 129.59 (Ar-C), 128.59 (Ar-C), 127.08 (Ar-C), 122.74(C6), 109.41 (C22), 80.93 (C16), 79.92 (C2"), 75.21 (C3), 66.98 (C26), 62.22, 56.55, 54.66, 50.05, 41.75, $40.39,39.84,38.59,38.01,37.00,36.85,32.18,31.98,31.53,30.44,28.95,28.45,27.78,20.94,19.45,17.28$, 16.41, 14.66. HRMS (ESI) $m / z: 662.4389[\mathrm{M}+\mathrm{H}]^{+}$, calcd for: $\mathrm{C}_{41} \mathrm{H}_{59} \mathrm{O}_{6} \mathrm{~N} 661.4389$.

$3 \beta$-(N-Cbz-L-valine)-diosgenin (Compound DG-8). Compound DG-8 was obtained as white powder by method 1, yield: $68.6 \%$; m.p.: $158.4{ }^{\circ} \mathrm{C},[\alpha]_{\mathrm{D}}^{25}=-80.00^{\circ}\left(\mathrm{c}=1.0 \mathrm{mg} / \mathrm{mL}, \mathrm{CHCl}_{3}\right) ;{ }^{1} \mathrm{H}-\mathrm{NMR}(500 \mathrm{MHz}$, $\left.\mathrm{CDCl}_{3}\right): \delta(\mathrm{ppm}) 7.31-7.37(\mathrm{~m}, 5 \mathrm{H}), 5.37(\mathrm{brs}, 1 \mathrm{H}), 5.27(\mathrm{~d}, J=9 \mathrm{~Hz}, 1 \mathrm{H}), 5.11(\mathrm{~s}, 2 \mathrm{H}), 4.67(\mathrm{~d}, J=9.5 \mathrm{~Hz}$, $1 \mathrm{H}), 4.39-4.43(\mathrm{~m}, 1 \mathrm{H}), 4.25-4.28(\mathrm{~m}, 1 \mathrm{H}), 3.46-3.49(\mathrm{~m}, 1 \mathrm{H}), 3.37(\mathrm{t}, J=11.0 \mathrm{~Hz}, 1 \mathrm{H}), 2.31(\mathrm{~d}, J=7.0$ $\mathrm{Hz}, 2 \mathrm{H}), 1.96-2.03(\mathrm{~m}, 2 \mathrm{H}), 1.04(\mathrm{~s}, 3 \mathrm{H}), 0.97(\mathrm{~d}, J=7.0 \mathrm{~Hz}, 6 \mathrm{H}), 1.00-2.00(\mathrm{~m}, 21 \mathrm{H}$, Sterane Structure); ${ }^{13} \mathrm{C}-\mathrm{NMR}\left(125 \mathrm{MHz}, \mathrm{CDCl}_{3}\right): \delta$ (ppm) $171.50\left(\mathrm{C1}^{\prime}\right), 156.37$ (C1"), 139.50 (C5), 128.68 (Ar-C), 128.32 (Ar-C), 122.81 (C6), 109.42 (C22), 80.94 (C16), 75.11 (C3), 67.11 (C2"), 66.99 (C26), 62.22, 59.16, 56.57, 50.06, 41.76, 40.40, 39.85, 38.18, 37.00, 36.85, 32.18, 31.98, 31.56, 31.52, 30.44, 28.95, 27.86, 20.95, 19.47, $19.08,17.62,17.28,16.42,14.66$. HRMS (ESI) $m / z: 648.4270[\mathrm{M}+\mathrm{H}]^{+}$, calcd for: $\mathrm{C}_{40} \mathrm{H}_{57} \mathrm{O}_{6} \mathrm{~N}$ 647.4270. 
33-(N-Cbz-L-lysine)-diosgenin (Compound DG-9). Compound DG-9 was obtained as white powder by method 1, yield: $68.6 \%$; m.p.: $135.8^{\circ} \mathrm{C},[\alpha]_{\mathrm{D}}^{25}=-43.56^{\circ}\left(\mathrm{c}=1.0 \mathrm{mg} / \mathrm{mL}, \mathrm{CHCl}_{3}\right) ;{ }^{1} \mathrm{H}-\mathrm{NMR}(500 \mathrm{MHz}$, $\left.\mathrm{CDCl}_{3}\right): \delta(\mathrm{ppm}) 7.30-7.35(\mathrm{~m}, 10 \mathrm{H}), 5.36(\mathrm{brs}, 1 \mathrm{H}), 5.08-5.12(\mathrm{~m}, 4 \mathrm{H}), 4.65(\mathrm{~d}, J=10.0 \mathrm{~Hz}, 1 \mathrm{H}), 4.39-4.43$ $(\mathrm{m}, 1 \mathrm{H}), 4.29-4.32(\mathrm{~m}, 1 \mathrm{H}), 3.46-3.48(\mathrm{~m}, 1 \mathrm{H}), 3.38(\mathrm{t}, J=11.0 \mathrm{~Hz}, 1 \mathrm{H}), 3.19(\mathrm{~d}, J=5.5 \mathrm{~Hz}, 2 \mathrm{H}), 2.29-2.30$ $(\mathrm{m}, 2 \mathrm{H}), 1.96-2.00(\mathrm{~m}, 2 \mathrm{H}), 1.43(\mathrm{~s}, 6 \mathrm{H}), 1.03(\mathrm{~s}, 3 \mathrm{H}), 0.97-0.98(\mathrm{~m}, 3 \mathrm{H}), 0.79(\mathrm{~d}, J=4.0 \mathrm{~Hz}, 6 \mathrm{H}), 1.00-2.00$ (m, 22H, Sterane Structure); ${ }^{13} \mathrm{C}-\mathrm{NMR}\left(125 \mathrm{MHz}, \mathrm{CDCl}_{3}\right): \delta(\mathrm{ppm}) 171.88\left(\mathrm{C1}^{\prime}\right), 156.60\left(\mathrm{C} 1^{\prime \prime}\right), 156.09$ (C1'”), 139.41 (C5), 136.71 (Ar-C), 136.40 (Ar-C), 128.65 (Ar-C), 128.22 (Ar-C), 122.87 (C6), 109.42 (C22), 80.93 (C16), 75.29 (C3), 67.12 (C2"), 66.99 (C2'"), 66.79 (C26), 62.21, 56.56, 53.87, 50.05, 41.75, 40.73, 40.39 , 39.85, 38.07, 36.99, 36.83, 32.52, 32.17, 31.98, 31.51, 30.44, 29.50, 28.95, 27.80, 27.05, 22.33, 20.95, 19.46, 17.28, 16.42, 14.66. HRMS (ESI) $m / z: 811.4846[\mathrm{M}+\mathrm{H}]^{+}$, calcd for: $\mathrm{C}_{49} \mathrm{H}_{66} \mathrm{O}_{8} \mathrm{~N}_{2} 810.4846$.

$3 \beta$-(glycine)-diosgenin (Compound DG-10). Compound DG-10 was obtained as white powder by method 2, yield: $56.7 \%$; m.p.: $110.8^{\circ} \mathrm{C},[\alpha]_{\mathrm{D}}^{25}=-82.05^{\circ}\left(\mathrm{c}=1.0 \mathrm{mg} / \mathrm{mL}, \mathrm{CHCl}_{3}\right) ;{ }^{1} \mathrm{H}-\mathrm{NMR}(500 \mathrm{MHz}$, Acetone-d6): $\delta(\mathrm{ppm}) 5.40(\mathrm{brs}, 1 \mathrm{H}), 4.54-4.60(\mathrm{~m}, 1 \mathrm{H}), 4.35-4.40(\mathrm{~m}, 1 \mathrm{H}), 3.40-3.43(\mathrm{~m}, 1 \mathrm{H}), 3.30(\mathrm{t}$, $J=11.0 \mathrm{~Hz}, 1 \mathrm{H}), 2.34(\mathrm{~d}, J=6.0 \mathrm{~Hz}, 2 \mathrm{H}), 2.09(\mathrm{~s}, 2 \mathrm{H}), 1.08(\mathrm{~s}, 3 \mathrm{H}), 0.96(\mathrm{~d}, J=7.0 \mathrm{~Hz}, 3 \mathrm{H}), 0.83(\mathrm{~s}, 3 \mathrm{H})$, $0.76(\mathrm{~d}, J=6.5 \mathrm{~Hz}), 1.00-2.00\left(\mathrm{~m}, 24 \mathrm{H}\right.$, Sterane Structure); ${ }^{13} \mathrm{C}-\mathrm{NMR}(125 \mathrm{MHz}$, Acetone- $d 6): \delta(\mathrm{ppm})$ 170.46 (C1'), 140.77 (C5), 123.01 (C6), 109.53 (C22), 81.44 (C16), 74.53 (C3), 67.22 (C26), 63.50, 57.24, 51.01, 42.39, 41.01, 40.44, 38.89, 37.81, 37.52, 32.76, 32.55, 32.30, 32.24, 31.12, 28.51, 21.57, 19.67, 17.47, 16.65, 15.04. HRMS (ESI) $m / z: 472.3399[\mathrm{M}+\mathrm{H}]^{+}$, calcd. for: $\mathrm{C}_{29} \mathrm{H}_{45} \mathrm{O}_{4} \mathrm{~N} 471.3399$.

3ß-(L-alanine)-diosgenin. (Compound DG-11). Compound DG-11was obtained as white powder by method 2, yield: $60.1 \%$; m.p.: $219.1^{\circ} \mathrm{C},[\alpha]_{\mathrm{D}}^{25}=-77.79^{\circ}\left(\mathrm{c}=1.0 \mathrm{mg} / \mathrm{mL}, \mathrm{CHCl}_{3}\right) ;{ }^{1} \mathrm{H}-\mathrm{NMR}(500 \mathrm{MHz}$, $\left.\mathrm{CDCl}_{3}\right): \delta(\mathrm{ppm}) 5.37(\mathrm{brs}, 1 \mathrm{H}), 4.60-4.65(\mathrm{~m}, 1 \mathrm{H}), 4.38-4.43(\mathrm{~m}, 1 \mathrm{H}), 3.48-3.53(\mathrm{~m}, 1 \mathrm{H}), 3.45-3.47(\mathrm{~m}$, $1 \mathrm{H}), 3.37(\mathrm{t}, J=11.0 \mathrm{~Hz}, 1 \mathrm{H}), 2.31(\mathrm{~d}, J=7.5 \mathrm{~Hz}, 2 \mathrm{H}), 1.95-2.02(\mathrm{~m}, 2 \mathrm{H}), 1.85-1.87(\mathrm{~m}, 2 \mathrm{H}), 1.33(\mathrm{~d}$, $J=7.0 \mathrm{~Hz}, 3 \mathrm{H}), 1.04(\mathrm{~s}, 3 \mathrm{H}), 0.97(\mathrm{~d}, J=7.0 \mathrm{~Hz}, 3 \mathrm{H}), 0.78(\mathrm{t}, J=3.0 \mathrm{~Hz}, 6 \mathrm{H}), 1.00-2.00(\mathrm{~m}, 20 \mathrm{H}$, Sterane Structure); ${ }^{13} \mathrm{C}-\mathrm{NMR}\left(125 \mathrm{MHz}, \mathrm{CDCl}_{3}\right): \delta$ (ppm) 176.06(C1'), 139.66 (C5), 122.65 (C6), 109.41 (C22), 80.93 (C16), 74.51 (C3), 66.98 (C26), 62.22, 56.57, 50.30, 50.07, 41.75, 40.39, 39.86, 38.15, 37.06, 36.86, $32.18,31.98,31.53,30.44,28.94,27.83,20.96,20.80,19.47,17.27,16.42,14.66$. HRMS (ESI) $m / z: 486.3554$ $[\mathrm{M}+\mathrm{H}]^{+}$, calcd for: $\mathrm{C}_{30} \mathrm{H}_{47} \mathrm{O}_{4} \mathrm{~N} 485.3554$.

$3 \beta$-(sarcosine)-diosgenin (Compound DG-12). Compound DG-12 was obtained as white powder by method 2, yield: $68.5 \%$; m.p.: $176.0^{\circ} \mathrm{C},[\alpha]_{\mathrm{D}}^{25}=-78.57^{\circ}\left(\mathrm{c}=1.0 \mathrm{mg} / \mathrm{mL}, \mathrm{CHCl}_{3}\right) ;{ }^{1} \mathrm{H}-\mathrm{NMR}(500 \mathrm{MHz}$, $\left.\mathrm{CDCl}_{3}\right): \delta(\mathrm{ppm}) 5.37$ (brs, $\left.1 \mathrm{H}\right), 4.64-4.70(\mathrm{~m}, 1 \mathrm{H}), 4.38-4.42(\mathrm{~m}, 1 \mathrm{H}), 3.44-3.47(\mathrm{~m}, 1 \mathrm{H}), 3.34-3.38(\mathrm{~m}$, $3 \mathrm{H}), 2.44(\mathrm{~s}, 3 \mathrm{H}), 2.33(\mathrm{~d}, J=7.5 \mathrm{~Hz}, 2 \mathrm{H}), 2.00(\mathrm{~s}, 1 \mathrm{H}), 1.84-1.87(\mathrm{~m}, 2 \mathrm{H}), 1.03(\mathrm{~s}, 3 \mathrm{H}), 0.96(\mathrm{~d}, J=7.0 \mathrm{~Hz}$, $3 \mathrm{H}), 0.78(\mathrm{t}, J=6.0 \mathrm{~Hz}, 6 \mathrm{H}), 1.00-2.00\left(\mathrm{~m}, 20 \mathrm{H}\right.$, Sterane Structure); ${ }^{13} \mathrm{C}-\mathrm{NMR}\left(125 \mathrm{MHz}, \mathrm{CDCl}_{3}\right): \delta$ (ppm) 171.71(C1'), 139.64 (C5), 122.67 (C6), 109.39 (C22), 80.91 (C16), 74.53 (C3), 66.96 (C26), 62.21, 56.55, 52.94, 50.05, 41.73, 40.38, 39.84, 38.22, 37.04, 36.84, 36.15, 32.16, 31.96, 31.52, 30.42, 28.93, 27.88, 20.94, 19.45, 17.26, 16.40, 14.65. HRMS (ESI) $m / z: 486.3545[\mathrm{M}+\mathrm{H}]^{+}$, calcd for: $\mathrm{C}_{30} \mathrm{H}_{47} \mathrm{O}_{4} \mathrm{~N} 485.3545$.

$3 \beta$-(L-proline)-diosgenin (Compound DG-13). Compound DG-13 was obtained as white powder by method 2, yield: $62.9 \%$; m.p.: $195.2^{\circ} \mathrm{C},[\alpha]_{\mathrm{D}}^{25}=-83.52^{\circ}\left(\mathrm{c}=1.0 \mathrm{mg} / \mathrm{mL}, \mathrm{CHCl}_{3}\right) ;{ }^{1} \mathrm{H}-\mathrm{NMR}(500 \mathrm{MHz}$, $\left.\mathrm{CDCl}_{3}\right): \delta(\mathrm{ppm}) 5.37(\mathrm{brs}, 1 \mathrm{H}), 4.61-4.66(\mathrm{~m}, 1 \mathrm{H}), 4.38-4.43(\mathrm{~m}, 1 \mathrm{H}), 3.71-3.74(\mathrm{~m}, 1 \mathrm{H}), 3.45-3.48(\mathrm{~m}$, $1 \mathrm{H}), 3.37(\mathrm{t}, J=11.0 \mathrm{~Hz}, 1 \mathrm{H}), 3.08-3.10(\mathrm{~m}, 1 \mathrm{H}), 2.89-2.91(\mathrm{~m}, 1 \mathrm{H}), 2.32(\mathrm{~d}, J=7.5 \mathrm{~Hz}, 2 \mathrm{H}), 2.11-2.15$ $(\mathrm{m}, 1 \mathrm{H}), 1.95-2.01(\mathrm{~m}, 2 \mathrm{H}), 1.03(\mathrm{~s}, 3 \mathrm{H}), 0.97(\mathrm{~d}, J=7.0 \mathrm{~Hz}, 3 \mathrm{H}), 0.78(\mathrm{t}, J=3.0 \mathrm{~Hz}, 6 \mathrm{H}), 1.00-2.00(\mathrm{~m}$, 24H, Sterane Structure); ${ }^{13} \mathrm{C}-\mathrm{NMR}\left(125 \mathrm{MHz}, \mathrm{CDCl}_{3}\right): \delta(\mathrm{ppm}) 174.98\left(\mathrm{C1}^{\prime}\right), 139.68(\mathrm{C} 5), 122.63(\mathrm{C} 6)$, 109.41 (C22), 80.93 (C16), 74.58 (C3), 66.98 (C26), 62.22, 60.04, 56.56, 50.06, 47.22, 41.75, 40.39, 39.85, $38.15,37.06,36.86,32.18,31.98,31.53,30.56,30.43,28.94,27.83,25.62,20.95,19.48,17.27,16.41,14.66$. HRMS (ESI) $m / z: 512.3701[\mathrm{M}+\mathrm{H}]^{+}$, calcd for: $\mathrm{C}_{32} \mathrm{H}_{49} \mathrm{O}_{4} \mathrm{~N} 511.3701$.

$3 \beta$-(L-leucine)-diosgenin (Compound DG-14). Compound DG-14 was obtained as white powder by method 2, yield: $66.5 \%$; m.p.: $154.4^{\circ} \mathrm{C},[\alpha]_{\mathrm{D}}^{25}=-94.55^{\circ}\left(\mathrm{c}=1.0 \mathrm{mg} / \mathrm{mL}, \mathrm{CHCl}_{3}\right) ;{ }^{1} \mathrm{H}-\mathrm{NMR}(500 \mathrm{MHz}$, Acetone- $d 6): \delta(\mathrm{ppm}) 5.40$ (brs, $1 \mathrm{H}), 4.51-4.55(\mathrm{~m}, 1 \mathrm{H}), 4.35-4.40(\mathrm{~m}, 1 \mathrm{H}), 4.09-4.11(\mathrm{~m}, 1 \mathrm{H}), 3.40-3.43$ $(\mathrm{m}, 1 \mathrm{H}), 3.30(\mathrm{t}, J=10.75 \mathrm{~Hz}, 1 \mathrm{H}), 2.32(\mathrm{~d}, J=7.5 \mathrm{~Hz}, 2 \mathrm{H}), 2.09(\mathrm{~s}, 1 \mathrm{H}), 1.07(\mathrm{~s}, 3 \mathrm{H}), 0.96(\mathrm{~d}, J=7.0 \mathrm{~Hz}$, 
$3 \mathrm{H}), 0.92(\mathrm{~d}, J=6.0 \mathrm{~Hz}, 3 \mathrm{H}), 0.86(\mathrm{~d}, J=7.0 \mathrm{~Hz}, 3 \mathrm{H}), 0.82(\mathrm{~s}, 3 \mathrm{H}), 0.76(\mathrm{~d}, J=6.5 \mathrm{~Hz}), 1.00-2.00(\mathrm{~m}, 26 \mathrm{H}$, Sterane Structure); ${ }^{13} \mathrm{C}-\mathrm{NMR}(125 \mathrm{MHz}$, Acetone- $d 6): \delta$ (ppm) $172.43\left(\mathrm{C1}^{\prime}\right), 140.88(\mathrm{C} 5), 123.17(\mathrm{C} 6)$, 109.67 (C22), 81.58 (C16), 74.60 (C3), 67.37 (C26), 63.64, 62.89, 57.38, 51.14, 43.36, 42.53, 41.15, 40.58, 39.00, 37.93, 37.66, 32.90, 32.69, 32.38, 31.26, 28.62, 25.63, 23.48, 22.57, 21.71, 19.83, 17.62, 16.80, 15.19 . HRMS (ESI) $m / z: 528.4016[\mathrm{M}+\mathrm{H}]^{+}$, calcd for: $\mathrm{C}_{33} \mathrm{H}_{53} \mathrm{O}_{4} \mathrm{~N} 527.4016$.

$3 \beta$-(L-isoleucine)-diosgenin (Compound DG-15). Compound DG-15 was obtained as white powder by method 2, yield: $70.2 \%$; m.p.: $147.1^{\circ} \mathrm{C},[\alpha]_{\mathrm{D}}^{25}=-76.34^{\circ}\left(\mathrm{c}=1.0 \mathrm{mg} / \mathrm{mL}, \mathrm{CHCl}_{3}\right) ;{ }^{1} \mathrm{H}-\mathrm{NMR}(500 \mathrm{MHz}$, Acetone-d6): $\delta$ (ppm) 5.41 (brs, $1 \mathrm{H}), 4.56-4.58(\mathrm{~m}, 1 \mathrm{H}), 4.37-4.40(\mathrm{~m}, 1 \mathrm{H}), 3.81-3.83(\mathrm{~m}, 1 \mathrm{H}), 3.41-3.43$ $(\mathrm{m}, 1 \mathrm{H}), 3.30(\mathrm{t}, J=11.0 \mathrm{~Hz}), 2.31(\mathrm{~d}, J=6.5 \mathrm{~Hz}, 2 \mathrm{H}), 2.09(\mathrm{~s}, 1 \mathrm{H}), 1.07(\mathrm{~s}, 3 \mathrm{H}), 0.96(\mathrm{~d}, J=7.0 \mathrm{~Hz}, 3 \mathrm{H})$, 0.85-0.97 (m, 6H), $0.83(\mathrm{~s}, 3 \mathrm{H}), 0.77(\mathrm{~d}, J=6.5 \mathrm{~Hz}, 3 \mathrm{H}), 1.00-2.00\left(\mathrm{~m}, 26 \mathrm{H}\right.$, Sterane Structure); ${ }^{13} \mathrm{C}-\mathrm{NMR}$ (125 MHz, Acetone- $d 6$ ): $\delta$ (ppm) $171.65\left(\mathrm{C1}^{\prime}\right), 140.84$ (C5), 123.17 (C6), 109.65 (C22), 81.56 (C16), 74.46 (C3), 69.76, 67.35 (C26), 63.62, 60.38, 57.36, 51.12, 42.52, 41.13, 40.56, 39.25, 39.06, 37.91, 37.65, 32.89, $32.68,32.37,31.25,28.65,25.91,21.70,19.81,17.61,16.79,16.11,15.18,12.01,11.83$. HRMS (ESI) $m / z$ : $528.4017[\mathrm{M}+\mathrm{H}]^{+}$, calcd for: $\mathrm{C}_{33} \mathrm{H}_{53} \mathrm{O}_{4} \mathrm{~N}$.

$3 \beta$-(L-phenylalanine)-diosgenin (Compound DG-16). Compound DG-16 was obtained as white powder by method 2, yield: $71.9 \%$; m.p.: $157.7^{\circ} \mathrm{C},[\alpha]_{\mathrm{D}}^{25}=-66.67^{\circ}\left(\mathrm{c}=1.0 \mathrm{mg} / \mathrm{mL}, \mathrm{CHCl}_{3}\right) ;{ }^{1} \mathrm{H}-\mathrm{NMR}(500 \mathrm{MHz}$, $\left.\mathrm{CDCl}_{3}\right): \delta(\mathrm{ppm}) \delta 7.20-7.31(\mathrm{~m}, 5 \mathrm{H}), 5.36(\mathrm{brs}, 1 \mathrm{H}), 4.60-4.62(\mathrm{~m}, 1 \mathrm{H}), 4.39-4.43(\mathrm{~m}, 1 \mathrm{H}), 3.69(\mathrm{~s}, 1 \mathrm{H})$, 3.46-3.48 (m, 1H), $3.37(\mathrm{t}, J=11.0 \mathrm{~Hz}, 1 \mathrm{H}), 3.04-3.08(\mathrm{~m}, 1 \mathrm{H}), 2.85-2.89(\mathrm{~m}, 1 \mathrm{H}), 2.23-2.24(\mathrm{~m}, 1 \mathrm{H}), 2.17(\mathrm{~s}$, $1 \mathrm{H}), 1.96-2.01(\mathrm{~m}, 2 \mathrm{H}), 1.02(\mathrm{~s}, 3 \mathrm{H}), 0.97(\mathrm{~d}, J=7.0 \mathrm{~Hz}, 3 \mathrm{H}), 0.78(\mathrm{brs}, 6 \mathrm{H}), 1.00-2.00(\mathrm{~m}, 21 \mathrm{H}$, Sterane Structure); ${ }^{13}$ C-NMR (125 MHz, Acetone- $\left.d 6\right): \delta$ (ppm) 174.56 (C1'), 139.67 (C5), 137.40 (Ar-C), 129.50 (Ar-C), 128.65 (Ar-C), 126.92 (Ar-C), 122.65 (C6), 109.41 (C22), 80.93 (C16), 74.68 (C3), 66.98 (C26), 62.22, 56.55, 56.02, 50.05, 41.74, 41.32, 40.39, 39.84, 38.06, 37.04, 36.85, 32.17, 31.97, 31.53, 30.43, 28.94, 27.83, 20.94, 19.45, 17.27, 16.41, 14.66. HRMS (ESI) $m / z: 562.3854[\mathrm{M}+\mathrm{H}]^{+}$, calcd for: $\mathrm{C}_{36} \mathrm{H}_{51} \mathrm{O}_{4} \mathrm{~N} 561.3854$.

$3 \beta$-(L-valine)-diosgenin (Compound DG-17). Compound DG-17 was obtained as white powder by method 2, yield: $58.2 \%$; m.p.: $139.1^{\circ} \mathrm{C},[\alpha]_{\mathrm{D}}^{25}=-69.72^{\circ}\left(\mathrm{c}=1.0 \mathrm{mg} / \mathrm{mL}^{2} \mathrm{CHCl}_{3}\right) ;{ }^{1} \mathrm{H}-\mathrm{NMR}(500 \mathrm{MHz}$, $\left.\mathrm{CDCl}_{3}\right): \delta(\mathrm{ppm}) 5.37(\mathrm{~s}, 1 \mathrm{H}), 4.64-4.66(\mathrm{~m}, 1 \mathrm{H}), 4.38-4.42(\mathrm{~m}, 1 \mathrm{H}), 3.45-3.47(\mathrm{~m}, 1 \mathrm{H}), 3.36(\mathrm{t}, J=11.0 \mathrm{~Hz}$, $1 \mathrm{H}), 2.32(\mathrm{~d}, J=6.5 \mathrm{~Hz}, 2 \mathrm{H}), 2.14-2.16(\mathrm{~m}, 2 \mathrm{H}), 1.03(\mathrm{~s}, 3 \mathrm{H}), 0.95(\mathrm{~d}, J=6.5 \mathrm{~Hz}, 6 \mathrm{H}), 0.91(\mathrm{~d}, J=7.0 \mathrm{~Hz}, 3 \mathrm{H})$, $0.78(\mathrm{~s}, 6 \mathrm{H}), 1.00-2.00\left(\mathrm{~m}, 24 \mathrm{H}\right.$, Sterane Structure); ${ }^{13} \mathrm{C}-\mathrm{NMR}(125 \mathrm{MHz}$, Acetone- $d 6): \delta(\mathrm{ppm}) 174.78$ (C1'), 139.64 (C5), 122.67 (C6), 109.41 (C22), 80.93 (C16), 74.44 (C3), 69.41, 66.97 (C26), 62.21, 59.94, 56.56, 50.07, 41.74, 40.38, 39.85, 38.25, 37.06, 36.86, 35.16, 32.17, 31.97, 31.52, 30.43, 28.94, 27.90, 20.94, 19.47, 19.38, 17.34, 17.27, 16.41, 14.65. HRMS (ESI) $\mathrm{m} / z: 514.3864[\mathrm{M}+\mathrm{H}]^{+}$, calcd for: $\mathrm{C}_{32} \mathrm{H}_{51} \mathrm{O}_{4} \mathrm{~N} 513.3864$.

$3 \beta$-(L-lysine)-diosgenin (Compound DG-18). Compound DG-18 was obtained as white powder by method 2, yield: $70.2 \%$; m.p.: $189.4^{\circ} \mathrm{C},[\alpha]_{\mathrm{D}}^{25}=-63.89^{\circ}\left(\mathrm{c}=1.0 \mathrm{mg} / \mathrm{mL}, \mathrm{CHCl}_{3}\right)$, yield: $64.6 \% .{ }^{1} \mathrm{H}-\mathrm{NMR}$ (500 MHz, $\left.\mathrm{CDCl}_{3}\right): \delta(\mathrm{ppm}) 5.37(\mathrm{brs}, 1 \mathrm{H}), 4.61-4.63(\mathrm{~m}, 1 \mathrm{H}), 4.37-4.42(\mathrm{~m}, 1 \mathrm{H}), 3.45-3.47(\mathrm{~m}, 1 \mathrm{H})$, 3.34-3.38 (m, 2H), 2.62-2.72 (m, 4H), $2.30(\mathrm{~d}, J=7.5 \mathrm{~Hz}, 2 \mathrm{H}), 2.16(\mathrm{~s}, 2 \mathrm{H}), 1.03(\mathrm{~s}, 3 \mathrm{H}), 0.96(\mathrm{~d}, J=7.0 \mathrm{~Hz}$, $3 \mathrm{H}), 0.77(\mathrm{~d}, J=3.5 \mathrm{~Hz}, 6 \mathrm{H}), 1.00-2.00\left(\mathrm{~m}, 28 \mathrm{H}\right.$, Sterane Structure); ${ }^{13} \mathrm{C}-\mathrm{NMR}\left(125 \mathrm{MHz}, \mathrm{CDCl}_{3}\right): \delta(\mathrm{ppm})$ 175.56 (C1'), 139.60 (C5), 122.69 (C6), 109.40 (C22), 80.91 (C16), 74.49 (C3), 66.96 (C26), 62.20, 56.55, 54.50, 50.05, 41.73, 40.37, 39.84, 38.18, 37.04, 36.84, 34.67, 32.16, 31.96, 31.51, 30.41, 28.92, 27.85, 23.01, 20.94, 19.46, 17.26, 16.40, 14.64. HRMS (ESI) $m / z: 543.4121[\mathrm{M}+\mathrm{H}]^{+}$, calcd for: $\mathrm{C}_{33} \mathrm{H}_{54} \mathrm{O}_{4} \mathrm{~N}_{2} 542.4121$.

\subsection{Bio-Evaluation Methods}

\subsubsection{Cell Culture}

SH-SY5Y cells and H9c2 cells were cultured in DMEM medium which were supplemented with $10 \%(V / V)$ fetal bovine serum (FBS) and $1 \%(V / V)$ penicillin-streptomycin (Thermo Technologies, New York, NY, USA). All of the cells were incubated in a humidified atmosphere containing $5 \% \mathrm{CO}_{2}$ at $37^{\circ} \mathrm{C}$. The positive drug (edaravone), diosgenin and diosgenin-amino acids derivatives DG- 1 to 18 were dissolved in DMSO (Sigma, St. Louis, MO, USA) and added at suitable concentrations to the cell culture. 


\subsubsection{Neuroprotective Activity Test Using SH-SY5Y Cell}

Analysis of neuroprotective effects was performed on SH-SY5Y cells via the MTT method. The SH-SY5Y cells in the logarithmic phase were plated into 96-well sterile plates at a density of $4.0 \times 10^{3}$ cells/well and cultured at $37{ }^{\circ} \mathrm{C}$ with $5 \% \mathrm{CO}_{2}$ containing incubator for $24 \mathrm{~h}$. The tested compounds $(0.1 \mathrm{~mL})$ were added to the treatment group cells in final concentrations ranging from 3.125 to $50 \mu \mathrm{M}$, while the TBHP treated cells and the control-differentiated cells were treated with the same amount of medium (DMEM medium which were supplemented with $10 \%(V / V)$ fetal bovine serum (FBS) and $1 \%(V / V)$ penicillin-streptomycin). The following day, the well of treatment group and TBHP treated cells were cultured with $350 \mu \mathrm{M}$ TBHP $(0.1 \mathrm{~mL})$ and incubated overnight. The control-differentiated cells were injected with new growth media at equal amounts. The cell culture fluid was replaced by $0.1 \mathrm{~mL}$ fresh medium before $20 \mu \mathrm{L}$ MTT solution $(5 \mathrm{mg} / \mathrm{mL})$ was added to each well. After $4 \mathrm{~h}$, the cell supernatant medium was removed by aspiration, then each well was given $0.15 \mathrm{~mL}$ DMSO and the plate was shaken $5 \mathrm{~min}$. The optical density (OD) for each well was read using a BIORAD 550 spectrophotometer (Bio-Rad Life Science Development Ltd., Beijing, China) plate reader at $490 \mathrm{~nm}$. All the results of damaged SH-SY5Y cells were carried out three times using replicate wells for each treatment. All the results of damaged SH-SY5Y cells were carried out three times using replicate wells for each treatment. The viability rates can be obtained from the following formula (1):

$$
\begin{gathered}
{\left[\mathrm{OD}_{490} \text { (Treatment group) }-\mathrm{OD}_{490}(\mathrm{TBHP} \text { damaged cells) }] /\left[\mathrm{OD}_{490}\right. \text { (Control group) - }\right.} \\
\mathrm{OD}_{490}(\mathrm{TBHP} \text { damaged cells) }) \times 100 \%
\end{gathered}
$$

The $\mathrm{EC}_{50}$ values were identified as the concentration of compound that could cause $50 \%$ of the individual effective drug concentration. The calculation formula (2) is as follows.

$$
-\mathrm{pEC}_{50}=\log \mathrm{C}_{\max }-\log 2 \times\left(\Sigma \mathrm{P}-0.75+0.25 \mathrm{P}_{\max }+0.25 \mathrm{P}_{\min }\right)
$$

where $C_{\max }$ is the maximum concentration, $\Sigma P$ is the sum of viability rates, $P_{\max }$ is the maximum value of the viability rate and $P_{\min }$ is the minimum value of the viability rate.

\subsubsection{Biosafety Evaluation Using H9c2 Cell}

The $\mathrm{H} 9 \mathrm{c} 2$ cells were transferred into individual wells of 96 -well plate $\left(4.0 \times 10^{3}\right.$ cells/well $)$ and cultured $24 \mathrm{~h}$ at $37^{\circ} \mathrm{C}$ with $5 \% \mathrm{CO}_{2}$. Compounds DG-13 and DG-15 dissolved in DMSO were added to each well with required concentrations $(3.125,6.25,12.5,25,50 \mu \mathrm{M})$. Then the control group were treated with the same volume of medium. The non-administered group were not treated (no cells and no medium). Then the sterile plates were further incubated for $4 \mathrm{~h}$, following MTT addition. After $4 \mathrm{~h}$, supernatant liquor was removed into the waste and all of the wells were then placed into the fresh DMSO $(0.15 \mathrm{~mL})$. The absorbance was measured using BIORAD 550 spectrophotometer with the emission wavelengths of $490 \mathrm{~nm}$. Each data was measured three times in parallel survival fraction of cells, calculated by the equation: $\left[\mathrm{OD}_{490}\right.$ (Drug group) - $\mathrm{OD}_{490}$ (non-administered group)]/[OD 490 (Control group) $-\mathrm{OD}_{490}$ (non-administered group) $] \times 100 \%$.

\subsubsection{Morphological Analysis Using Giemsa and DAPI Staining}

The SH-SY5Y cells were seeded in 12-well sterile plates at a density of $3.0 \times 10^{4}$ cells per well and placed at $37^{\circ} \mathrm{C}$ in a $5 \% \mathrm{CO}_{2}$ containing incubator for $24 \mathrm{~h}$. Afterwards, the medium containing compound DG-15 were added to the cultures for $24 \mathrm{~h}$ and the concentration range of the examined compounds was 10, 20 and $40 \mu \mathrm{M}$. Then $0.1 \mathrm{~mL}$ TBHP was used to damage cells and the plate was cultured for further $24 \mathrm{~h}$. Removing the culture medium, washing twice with PBS and fixing cells with $2 \mathrm{~mL}$ methanol for $2 \mathrm{~min}$ and $1 \mathrm{~mL}$ paraformaldehyde for $15 \mathrm{~min}$ respectively and washed with fresh PBS again. Giemsa solution or DAPI was added to stain the fixed cells for 2 min and 
protected from light. Finally, the cells ware washed with water and were observed under inverted fluorescent microscope.

\subsubsection{Neuroprotective Activity Test Using CAM model}

The CAM was examined as a predictive model for the angiogenic activity studies of compounds DG-15. The wide end of the fresh fertilized egg was placed upward in an incubator at $37^{\circ} \mathrm{C}$ with a relative humidity of $60 \%$. All the eggs were turned every two hours to prevent from sticking to each other. Compound DG-15 was dissolved with acetone at a concentration of $1 \mathrm{mg} / \mathrm{mL}$ and $4 \mathrm{mg} / \mathrm{mL}$ and then $5 \mu \mathrm{L}$ solution was transferred to gelatin sponge using a pipette respectively. The sham treatment group was added to the same volume of saline. Disinfected with UV lamp for $30 \mathrm{~min}$. After 7 days, the broader said of eggs was disinfected with $70 \%$ alcohol, then a 30-mm-diameter window was carefully opened in the shell to reduce the chamber pressure before removed the upper shell membrane with tweezers. In addition, the non-fertilized oocytes and unhealthy developed embryos were thrown away. Then the gelatin sponge was embedded into the allantoic membrane and the window was sealed with adhesive tape, with the eggs being returned to the incubator. The eggs were then incubated 3 days after administration, fixed with methanol-acetone (1:1) for $10 \mathrm{~min}$ and repeated four times. In the end, the allantoic membrane was cut out, placed in deionized water and tiled on a glass slide. The vascular growth was analyzed with a dissecting microscope and counted by software of Image Professional Plus 5.0 software (Media Cybernetics, Inc, MD, USA)

\subsection{Statistical Analysis}

All experimental data were expressed as the means \pm standard deviation (SD) of three replicates. The statistical analysis was performed by the software of SPSS (Version 20.0, International Business Machines Corp. New York, NY, USA) to calculate the variance. One-way analysis of variance (ANOVA) was performed to determine the significance between groups. A $p$-value of less than 0.05 was deemed to be significant.

\section{Conclusions}

In summary, eighteen diosgenin-amino acid derivatives were designed and synthesized by esterification reaction and deprotection reaction, respectively. The structures of all compounds were verified by ${ }^{1} \mathrm{H}-\mathrm{NMR},{ }^{13} \mathrm{C}-\mathrm{NMR}$, HRMS. Then the MTT method was used for investigating the neuroprotective activity on the damaged SH-SY5Y cells and biological safety on H9c2 cells. The result indicated that DG-15 has a stronger neuroprotective activity and lower cytotoxicity than diosgenin. Interestingly, diosgenin attached to different types of amino acids, with and without protective groups, has different neuroprotective activities. And further Giemsa and DAPI staining explains the effect of compounds DG-15 on SH-SY5Y from the perspective of cell morphology. We also conducted a preliminary evaluation of the angiogenesis effect of the compounds DG-15 using the CAM model. The result proved that it could promote the formation of tiny blood vessels in chicken embryos damaged by TBHP. We conceive that this study could promote the attempt to discover more efficient and double-effective leading compounds from natural products.

Supplementary Materials: The following are available online, Figure: ${ }^{1} \mathrm{H}-\mathrm{NMR}$ and ${ }^{13} \mathrm{C}-\mathrm{NMR}$ spectra of compound 1-18.

Author Contributions: Data curation, W.G., X.H., F.G. and H.C.; Investigation, T.L. and G.L.; Methodology, Y.Y., W.Z., F.Z. and X.J.; Project administration, Y.Z. and H.L.; Supervision, P.W.; Writing—original draft, D.C.; Writing-review \& editing, J.Q.

Funding: This research was funded by the National Natural Science Foundation of China (No. 81603256), project of China Association of Chinese Medicine (CACM-2018-QNRC2-B08), the Fundamental Research Funds for the Central Universities (BUCM-2019-JCRC002, BUCM-2018-2020 and 2019-JYB-TD005), Beijing Key Laboratory for Basic and Development Research on Chinese Medicine (Beijing, 100102). 
Acknowledgments: This study was supported by Chinese Academy of Inspection and Quarantine, Beijing Institute of Technology and Capital Normal University.

Conflicts of Interest: The authors declare that the research was conducted in the absence of any commercial or financial relationships that could be construed as a potential conflict of interest.

\section{References}

1. Wang, P.; Xu, T.Y.; Guan, Y.F.; Tian, W.W.; Viollet, B.; Rui, Y.C.; Miao, C.Y. Nicotinamide phosphoribosyltransferase protects against ischemic stroke through SIRT1-dependent adenosine monophosphate-activated kinase pathway. Ann. Neurol. 2011, 69, 360-374. [CrossRef] [PubMed]

2. Zhang, X.; Xue, X.; Xian, L.; Guo, Z.; Ito, Y.; Sun, W. Potential neuroprotection of protodioscin against cerebral ischemia-reperfusion injury in rats through intervening inflammation and apoptosis. Steroids 2016, 113, $52-63$. [CrossRef] [PubMed]

3. Wang, Q.; Tang, X.N.; Yenari, M.A. The inflammatory response in stroke. J. Neuroimmunol. 2007, 184, 53-68. [CrossRef] [PubMed]

4. Manuel, G.E.; Johnson, T.; Liu, D. Therapeutic angiogenesis of exosomes for ischemic stroke. Int. J. Physiol. Pathophysiol. Pharmacol. 2017, 9, 188.

5. Selvamani, A.; Sathyan, P.; Miranda, R.C.; Sohrabji, F. An antagomir to microRNA Let7f promotes neuroprotection in an ischemic stroke model. PLoS ONE 2012, 7, e32662. [CrossRef]

6. Liu, Z.; Chopp, M. Astrocytes, therapeutic targets for neuroprotection and neurorestoration in ischemic stroke. Prog. Neurobiol. 2016, 144, 103-120. [CrossRef]

7. Sautour, M.; Mitaine-Offer, A.C.; Lacaille-Dubois, M.A. The Dioscorea genus: A review of bioactive steroid saponins. J. Nat. Med. 2007, 61, 91-101. [CrossRef]

8. Zhang, X.; Xue, X.; Zhao, J.; Qian, C.; Guo, Z.; Ito, Y.; Sun, W. Diosgenin attenuates the brain injury induced by transient focal cerebral ischemia-reperfusion in rats. Steroids 2016, 113, 103-112. [CrossRef]

9. Zhang, B.; Chen, Y.; Yang, B.; Jiang, F.; Zhao, J.; Ouyang, Z. Neuroprotective effects of diosgenin in rats with experimental spinal cord injury via promotion of autophagy. Int. J. Clin. Exp. Med. 2017, 10, 11655-11663.

10. Zhang, X.; Jin, M.; Tadesse, N.; Dang, J.; Zhou, T.; Zhang, H.; Ito, Y. Dioscorea zingiberensis CH Wright: An overview on its traditional use, phytochemistry, pharmacology, clinical applications, quality control and toxicity. J. Ethnopharmacol. 2018, 220, 283-293. [CrossRef]

11. Jesus, M.; Martins, A.P.; Gallardo, E.; Silvestre, S. Diosgenin: Recent highlights on pharmacology and analytical methodology. J. Anal. Methods Chem. 2016, 2016, 16. [CrossRef] [PubMed]

12. Patel, K.; Gadewar, M.; Tahilyani, V.; Patel, D.K. A review on pharmacological and analytical aspects of diosgenin: A concise report. Nat. Prod. Bioprospecting 2012, 2, 46-52. [CrossRef]

13. Zheng, H.; Youdim, M.B.; Weiner, L.M.; Fridkin, M. Novel potential neuroprotective agents with both iron chelating and amino acid-based derivatives targeting central nervous system neurons. Biochem. Pharmacol. 2005, 70, 1642-1652. [CrossRef] [PubMed]

14. Cai, E.; Guo, S.; Yang, L. Synthesis and antitumour activity of arctigenin amino acid ester derivatives against H22 hepatocellular carcinoma. Nat. Prod. Res. 2018, 32, 406-411. [CrossRef]

15. Wu G, R.; Xu, B.; Yang Y, Q. Synthesis and biological evaluation of podophyllotoxin derivatives as selective antitumor agents. Eur. J. Med. Chem. 2018, 155, 183-196. [CrossRef]

16. Gong, G.; Qin, Y.; Huang, W. Anti-thrombosis effect of diosgenin extract from Dioscorea zingiberensis $\mathrm{CH}$ Wright in vitro and in vivo. Phytomedicine 2011, 18, 458-463. [CrossRef]

17. Lee, B.K.; Kim, C.J.; Shin, M.S.; Cho, Y.S. Diosgenin improves functional recovery from sciatic crushed nerve injury in rats. J. Exerc. Rehabil. 2018, 14, 566. [CrossRef]

18. Dias, K.L.G.; de Azevedo Correia, N.; Pereira, K.K.G.; Barbosa-Filho, J.M.; Cavalcante, K.V.M.; Araújo, I.G.A.; Medeiros, I.A. Mechanisms involved in the vasodilator effect induced by diosgenin in rat superior mesenteric artery. Eur. J. Pharmacol. 2007, 574, 172-178. [CrossRef]

19. Zheng, H.; Wei, Z.; Xin, G.; Ji, C.; Wen, L.; Xia, Q.; Huang, W. Preventive effect of a novel diosgenin derivative on arterial and venous thrombosis in vivo. Bioorganic Med. Chem. Lett. 2016, 26, 3364-3369. [CrossRef] 
20. Wei, Z.; Xin, G.; Wang, H.; Zheng, H.; Ji, C.; Gu, J.; Huang, W. The diosgenin prodrug nanoparticles with $\mathrm{pH}$-responsive as a drug delivery system uniquely prevents thrombosis without increased bleeding risk. Nanomed. Nanotechnol. Biol. Med. 2018, 14, 673-684. [CrossRef]

21. Okawara, M.; Hashimoto, F.; Todo, H.; Sugibayashi, K.; Tokudome, Y. Effect of liquid crystals with cyclodextrin on the bioavailability of a poorly water-soluble compound, diosgenin, after its oral administration to rats. Int. J. Pharm. 2014, 472, 257-261. [CrossRef] [PubMed]

22. Wang, S.; Wang, F.; Yang, H.; Li, R.; Guo, H.; Hu, L. Diosgenin glucoside provides neuroprotection by regulating microglial M1 polarization. Int. Immunopharmacol. 2017, 50, 22-29. [CrossRef] [PubMed]

23. Kim, D.H.; Hong, B.N.; Le, H.T.; Hong, H.N.; Lim, C.W.; Park, K.H.; Kang, T.H. Small molecular weight PEGylation of diosgenin in an in vivo animal study for diabetic auditory impairment treatment. Bioorganic Med. Chem. Lett. 2012, 22, 4609-4612. [CrossRef] [PubMed]

24. Beaulieu, R.; Gottis, S.; Meyer, C.; Grand, E.; Deveaux, V.; Kovensky, J.; Stasik, I. Cholesteryl and diosgenyl glycosteroids: Synthesis and characterization of new smectic liquid crystals. Carbohydr. Res. 2015, 404, 70-78. [CrossRef]

25. Deng, S.; Yu, B.; Hui, Y.; Yu, H.; Han, X. Synthesis of three diosgenyl saponins: Dioscin, polyphyllin D and balanitin 7. Carbohydr. Res. 1999, 317, 53-62. [CrossRef]

26. Ullah, A.; Iftikhar, F.; Arfan, M.; Batool Kazmi, S.T.B.; Anjum, M.N.; Haq, I.U.; Haq, I.; Ayaz, M.; Farooq, S.; Rashid, U. Amino acid conjugated antimicrobial drugs: Synthesis, lipophilicity- activity relationship, antibacterial and urease inhibition activity. Eur. J. Med. Chem. 2018, 145, 140-153. [CrossRef]

27. Mi, K.K.; Park, K.S.; Yeo, W.S.; Choo, H.; Chong, Y. In vitro solubility, stability and permeability of novel quercetin-amino acid conjugates. Bioorganic Med. Chem. 2009, 17, 1164-1171.

28. Suhas, R.; Chandrashekar, S.; Gowda, D.C. Synthesis of uriedo and thiouriedo derivatives of peptide conjugated heterocycles -A new class of promising antimicrobials. Eur. J. Med. Chem. 2012, 48, 179-191. [CrossRef]

29. Vardhan, D.M.S.; Shantharam, C.S.; Ramesh, S.; Sridhara, M.B.; Gowda, D.C. Synthesis and SAR studies of urea and thiourea derivatives of gly/pro conjugated to piperazine analogue as potential AGE inhibitors. Protein Pept. Lett. 2013, 20, 888-897. [CrossRef]

30. Fang, L.; Wang, M.; Gou, S.; Liu, X.; Zhang, H.; Cao, F. Combination of amino acid/dipeptide with nitric oxide donating oleanolic acid derivatives as PepT1 targeting antitumor prodrugs. J. Med. Chem. 2014, 57, 1116-1120. [CrossRef]

31. Schmeda-Hirschmann, G.; Rodríguez, J.A.; Theoduloz, C.; Valderrama, J.A. Gastroprotective effect and cytotoxicity of labdeneamides with amino acids. Planta Med. 2011, 77, 340-345. [CrossRef] [PubMed]

32. Kang, F.; Zhang, X.H.; Han, Y.T.; Wu, G.R.; Cai, D.S.; Xue, N.N.; Guo, W.B.; Yang, Y.Q.; Chen, M.; Zhang, X.Y.; et al. Design, Synthesis and Cytotoxic Analysis of Novel Hederagenin-Pyrazine Derivatives Based on Partial Least Squares Discriminant Analysis. Int. J. Mol. Sci. 2018, 19, 2994.

33. Tanabe, M.; Nitta, A.; Ono, H. Neuroprotection via strychnine-sensitive glycine receptors during post-ischemic recovery of excitatory synaptic transmission in the hippocampus. J. Pharmacol. Sci. 2010, 1007220421. [CrossRef]

34. Pinto, M.C.X.; Simão, F.; da Costa, F.L.P.; Rosa, D.V.; de Paiva, M.J.N.; Resende, R.R.; Romano-Silva, M.A.; Gomez, M.V.; Gomez, R.S. Sarcosine preconditioning induces ischemic tolerance against global cerebral ischemia. Neuroscience 2014, 271, 160-169. [CrossRef] [PubMed]

35. Pinto, M.C.X.; Mourão, F.A.G.; Binda, N.S.; Leite, H.R.; Gomez, M.V.; Massensini, A.R.; Gomez, R.S. Pharmacological induction of ischemic tolerance in hippocampal slices by sarcosine preconditioning. Neurochem. Int. 2012, 61, 713-720. [CrossRef]

36. Koh, S.H.; Kim, S.H. Role of Oxidative Stress in Neurodegenerative Diseases and Ischemic Stroke and Prospects of Antioxidant Therapies as a New Therapeutic Strategy. Hanyang Med. Rev. 2006, 26, 133-143.

37. Sun, G.; Wang, J.; Guo, X.; Lei, M.; Zhang, Y.; Wang, X.; Hu, L. Design, synthesis and biological evaluation of LX2343 derivatives as neuroprotective agents for the treatment of Alzheimer's disease. Eur. J. Med. Chem. 2018, 145, 622-633. [CrossRef]

38. Seetapun, S.; Yaoling, J.; Wang, Y.; Zhu, Y.Z. Neuroprotective effect of Danshensu derivatives as anti-ischaemia agents on SH-SY5Y cells and rat brain. Biosci. Rep. 2013, 33, 677-688. [CrossRef] 
39. Shin, E.S.; Kim, Y.J.; Kang, K.A.; Lee, J.; Jeon, J.Y. Effects of Erythropoietin in Hypoxia-Induced Ischemia on Differentiated Human Neuroblastoma SH-SY5Y and Rat Stroke Model. Korean J. Psychopharmacol. 2010, 21, 22-28.

40. Liu, W.; Feng, G.S.; Ou, Y.; Xu, J.; Zhang, Z.J.; Zhang, G.X.; Jiang, J. Neuroprotective effect of apocynin nitrone in oxygen glucose deprivation-treated SH-SY5Y cells and rats with ischemic stroke. Trop. J. Pharm. Res. 2016, 15, 1681-1689. [CrossRef]

41. Chen, J.; Shi, X.; Chen, Y.; Liang, H.; Cheng, C.; He, Q. Neuroprotective effects of chloroform and aqueous fractions of noni juice against $\mathrm{t}$-Butyl hydroperoxide-induced oxidative damage in SH-SY5Y cells. Food Nutr. Res. 2018, 62. [CrossRef] [PubMed]

42. Awad, H.M.; Abd-Alla, H.I.; Mahmoud, K.H.; El-Toumy, S.A. In vitro anti-nitrosative, antioxidant and cytotoxicity activities of plant flavonoids: A comparative study. Med. Chem. Res. 2014, 23, 3298-3307. [CrossRef]

43. Richardson, M.; Singh, G. Observations on the use of the avian chorioallantoic membrane (CAM) model in investigations into angiogenesis. Curr. Drug Targets-Cardiovasc. Hematol. Disord. 2003, 3, 155-185. [CrossRef]

44. Kue, C.S.; Tan, K.Y.; LaM, M.L.; Lee, H.B. Chick embryo chorioallantoic membrane (CAM): An alternative predictive model in acute toxicological studies for anti-cancer drugs. Exp. Anim. 2015, 14-0059. [CrossRef] [PubMed]

45. Davis, C.K.; Nampoothiri, S.S.; Rajanikant, G.K. Folic acid exerts post-ischemic neuroprotection in vitro through HIF-1 $\alpha$ stabilization. Mol. Neurobiol. 2018, 55, 8328-8345. [CrossRef] [PubMed]

46. Zou, J.; Chen, Z.; Wei, X.; Chen, Z.; Fu, Y.; Yang, X.; Li, M. Cystatin C as a potential therapeutic mediator against Parkinson's disease via VEGF-induced angiogenesis and enhanced neuronal autophagy in neurovascular units. Cell Death Dis. 2017, 8, e2854. [CrossRef] [PubMed]

47. Ma, W.; Wang, S.; Liu, X.; Tang, F.; Zhao, P.; Cheng, K.; Feng, W. Protective effect of troxerutin and cerebroprotein hydrolysate injection on cerebral ischemia through inhibition of oxidative stress and promotion of angiogenesis in rats. Mol. Med. Rep. 2019, 19, 3148-3158. [CrossRef]

48. Li, B.; Yan, W.; Zhang, C.; Zhang, Y.; Liang, M.; Chu, F.; Gong, Y.; Xu, B.; Wang, P.; Lei, H. New synthesis method for sultone derivatives: Synthesis, crystal structure and biological evaluation of S-CA. Molecules 2015, 20, 4307-4318. [CrossRef]

49. Wang, P.L.; Cheng, Y.T.; Xu, K.; An, Y.W.; Wang, W.; Li, Q.S.; Zhang, H.G.; Lei, H.M. Synthesis and Antitumor Evaluation of One Novel Tetramethylpyrazine-Rhein Derivative. Asian J. Chem. 2013, 25, 4885-4888. [CrossRef]

50. Wang, P.; She, G.; Yang, Y.; Li, Q.; Zhang, H.; Liu, J.; Gao, Y.; Xu, X.; Lei, H. Synthesis and biological evaluation of new ligustrazine derivatives as anti-tumor agents. Molecules 2012, 17, 4972-4985. [CrossRef]

51. Krupinski, J.; Kaluza, J.; Kumar, P.; Kumar, S.; Wang, J.M. Role of angiogenesis in patients with cerebral ischemic stroke. Stroke 1994, 25, 1794-1798. [CrossRef] [PubMed]

52. Chen, J.; Zhang, Z.G.; Li, Y.; Wang, L.; Xu, Y.X.; Gautam, S.C.; Chopp, M. Intravenous administration of human bone marrow stromal cells induces angiogenesis in the ischemic boundary zone after stroke in rats. Circ. Res. 2003, 92, 692-699. [CrossRef] [PubMed]

53. Xia, C.F.; Yin, H.; Yao, Y.Y.; Borlongan, C.V.; Chao, L.; Chao, J. Kallikrein protects against ischemic stroke by inhibiting apoptosis and inflammation and promoting angiogenesis and neurogenesis. Hum. Gene Ther. 2006, 17, 206-219. [CrossRef] [PubMed]

54. Navarro-Sobrino, M.; Rosell, A.; Hernández-Guillamon, M.; Penalba, A.; Boada, C.; Domingues-Montanari, S.; Montaner, J. A large screening of angiogenesis biomarkers and their association with neurological outcome after ischemic stroke. Atherosclerosis 2011, 216, 205-211. [CrossRef]

55. Beck, H.; Plate, K.H. Angiogenesis after cerebral ischemia. Acta Neuropathol. 2009, 117, 481-496. [CrossRef]

56. Grasso, G.; Santoro, A.M.; Lanza, V.; Sbardella, D.; Tundo, G.R.; Ciaccio, C.; Marini, S.; Coletta, M.; Milardi, D. The double faced role of copper in A $\beta$ homeostasis: A survey on the interrelationship between metal dyshomeostasis, UPS functioning and autophagy in neurodegeneration. Coord. Chem. Rev. 2017, 347, 1-22. [CrossRef]

57. Arena, G.; Fattorusso, R.; Grasso, G.; Grasso, G.I.; Isernia, C.; Malgieri, G.; Milardi, D.; Rizzarelli, E. Zinc (II) complexes of ubiquitin: Speciation, affinity and binding features. Chem. A Eur. J. 2011, 17, 11596-11603. [CrossRef] 
58. Milewski, K.; Hilgier, W.; Fręśko, I.; Polowy, R.; Podsiadłowska, A.; Zołocińska, E.; Grymanowska, A.W.; Filipkowski, R.K.; Albrecht, J.; Zielińska, M. Carnosine reduces oxidative stress and reverses attenuation of righting and postural reflexes in rats with thioacetamide-induced liver failure. Neurochem. Res. 2016, 41, 376-384. [CrossRef]

59. Drąg-Zalesińska, M.; Drag, M.; Poręba, M.; Borska, S.; Kulbacka, J.; Saczko, J. Anticancer properties of ester derivatives of betulin in human metastatic melanoma cells (Me-45). Cancer Cell Int. 2017, 17, 4. [CrossRef]

Sample Availability: Samples of the compounds 1-18 are available from the authors.

(C) 2019 by the authors. Licensee MDPI, Basel, Switzerland. This article is an open access article distributed under the terms and conditions of the Creative Commons Attribution (CC BY) license (http://creativecommons.org/licenses/by/4.0/). 